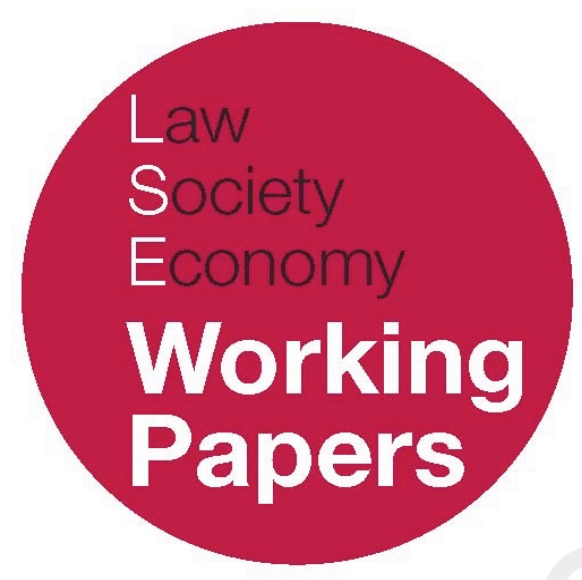

\title{
The TRIPS Intellectual Property Waiver \\ Proposal: Creating the Right Incentives in Patent Law and Politics to end the COVID-19 \\ Pandemic
}

\begin{abstract}
Siva Thambisetty, Aisling McMahon, Luke McDonagh, Hyo Yoon Kang, Graham Dutfield
\end{abstract}

LSE Law, Society and Economy Working Papers 06/2021

London School of Economics and Political Science

Law Department

This paper can be downloaded without charge from LSE Law, Society and Economy Working Papers at: www.lse.ac.uk/collections/law/wps/wps.htm and the Social Sciences Research Network electronic library at: $\underline{\text { https: } / / \text { ssrn.com/abstract }=3851737 .}$.

(C) Siva Thambisetty, Aisling McMahon, Luke McDonagh, Hyo Yoon Kang, Graham Dutfield. Users may download and/or print one copy to facilitate their private study or for noncommercial research. Users may not engage in further distribution of this material or use it for any profit-making activities or any other form of commercial gain. 


\title{
The TRIPS Intellectual Property Waiver Proposal: Creating the Right Incentives in Patent Law and Politics to end the COVID- 19 Pandemic
}

\author{
Siva Thambisetty, Aisling McMahon, Luke McDonagh, Hyo Yoon Kang, \\ Graham Dutfield*
}

\begin{abstract}
:
The structure of global intellectual property law as incorporated in the World Trade Organization (WTO) Agreement on Trade-Related Aspects of Intellectual Property Rights (TRIPS) is implicated in the current lack of COVID-19 vaccines, medical equipment, medicines and diagnostics needed to combat the pandemic. In this paper, we elucidate the legal issues surrounding the 'TRIPS waiver' proposal initially put forward by India and South Africa in October 2020, which, as of June 2021, is supported by more than 60 states. We analyse the different intellectual property rights relevant to the proposal - focusing primarily on patent rights and trade secrets - which are most relevant to the present COVID-19 vaccine context. We explain why the existing TRIPS flexibilities around compulsory licensing are incapable of addressing the present pandemic context adequately, in terms of both procedure and legal substance. Given the ongoing absence of sufficient engagement by the pharmaceutical industry with proposed global mechanisms to share intellectual property rights, data and know-how to address the pandemic, we argue that both incentives and mandatory mechanisms are needed.

We make two arguments to this effect: first, the TRIPS waiver is a necessary and proportionate legal measure for clearing intellectual property (IP) barriers in a direct, consistent and efficient fashion, enabling the freedom to operate for more companies to produce COVID-19 vaccines and other health technologies without the fear of infringing another party's IP rights and the attendant threat of litigation; and second, the TRIPS waiver acts as an important political, moral and economic lever towards encouraging solutions aimed at global equitable access to vaccines, which is in the wider interest of the global public. The TRIPS waiver is an essential legal instrument in this context for enabling a radical increase in manufacturing capacity, and hence supply, of COVID-19 vaccines, creating a pathway to achieve global equitable production and access.
\end{abstract}

* Authors listed in reverse alphabetical order: Siva Thambisetty (London School of Economics), Aisling McMahon (Maynooth University), Luke McDonagh (London School of Economics), Hyo Yoon Kang (University of Kent), Graham Dutfield (University of Leeds). 


\section{INTRODUCTION}

The structure of global intellectual property law as incorporated in the World Trade Organization (WTO) Agreement on Trade-Related Aspects of Intellectual Property Rights (TRIPS) is implicated in the current lack of COVID-191 vaccines, medical equipment, medicines and diagnostics (hereafter, 'health technologies'), which are needed to combat the pandemic. ${ }^{2}$ Although equitable access to vaccines is in the moral, political and economic interests of the global public and requires global solidarity, ${ }^{3}$ the phenomenon of COVID-19 'vaccine nationalism' has brought into sharp relief the misalignment of current legal and financial incentives to produce and distribute vaccines equitably. ${ }^{4}$ The crisis further demonstrates the failure of high-income countries (HICs) to realise the promise they made at the time of the TRIPS negotiations in 1994, that by agreeing to the terms of TRIPS, lower and middle-income countries (LMICs) would benefit from technology transfer and the building of productive capacity..$^{5}$ As such, the current crisis is revealing not only of inadequacies of how to deal with global emergencies, but also of deficiencies within the international 'patent bargain' itself. 6

This paper elucidates the legal issues surrounding the 'TRIPS waiver' proposal initially put forward by India and South Africa in October 2020, ${ }^{7}$ which, as of May 2021, is supported by more than 60 states, ${ }^{8}$ and has received statements of support from the World Health Organization (WHO). ${ }^{9}$ We analyse the different intellectual property rights relevant

1 Severe acute respiratory syndrome coronavirus 2 (SARS-CoV-2) hereafter 'COVID-19'.

2 This article focuses primarily on vaccines - which should not be taken as downplaying the importance of the various other health technologies whose diffusion is also crucially important in combatting Covid-19. See Agreement on Trade-Related Aspects of Intellectual Property Rights (TRIPS), Annex 1C of the Marrakesh Agreement Establishing the World Trade Organization (WTO) (1994).

3 S Thambisetty, 'Vaccines and Patents: How Self-Interest and Artificial Scarcity Weaken Human Solidarity' LSE Covid-19 blog (March 2021) https://blogs.lse.ac.uk/covid19/2021/02/11/vaccines-and-patents-how-selfinterest-and-artificial-scarcity-weaken-human-solidarity/

4 HY Kang, 'Patent Capital in the Covid-19 Pandemic' Critical Legal Thinking blog (March 2021) https://criticallegalthinking.com/2021/02/09/patent-capital-in-the-covid-19-pandemic-critical-intellectualproperty-law/

5 A Orford, 'Broken Bargains' LRB Blog (May 2021) https://www.lrb.co.uk/blog/2021/may/broken-bargains

${ }^{6} \mathrm{KC}$ Shadlen, S Guennif, A Guzmán and N Lalitha (Eds.), Intellectual Property, Pharmaceuticals and Public Health: Access to Drugs in Developing Countries (Edward Elgar, 2011).

7 Waiver from Certain Provisions of the TRIPS Agreement for the Prevention, Containment and Treatment of Covid-19. Communication from India and South Africa (2 Oct 2020) IP/C/W/669 https://docs.wto.org/dol2fe/Pages/SS/directdoc.aspx?filename=q:/IP/C/W669.pdf\&Open=True (accessed 24th May 2021). See also revised TRIPS waiver text of 21 May 2021 https://www.keionline.org/wpcontent/uploads/W669Rev1.pdf

8 There are currently moves in Europe considering whether the EU would also support the waiver proposal; on 20 May, in a non-binding vote, the European Parliament voted in favour of a proposal for the EU to support the waiver https://twitter.com/amnesty/status/1395341916053639168?s=20 European Parliament, 'Covid-19 Vaccines: MEPs clash on proposed waiver of patents' (19 May 2021) https://www.europarl.europa.eu/news/en/headlines/society/20210512STO04016/covid-19-vaccines-mepsclash-on-proposed-waiver-of-patents; a result on this is expected to be put to a vote in the EU Commission 710 June meeting https://www.europarl.europa.eu/news/en/agenda/briefing/2021-05-17/0/parliament-todiscuss-call-for-waiver-of-covid-19-vaccine-patents

9 World Health Organization (WHO), 'WHO Director-General Commends United States Decision to Support Temporary Waiver on Intellectual Property Rights for Covid-19 Vaccines’ (5 May 2021)

https://www.who.int/news/item/05-05-2021-who-director-general-commends-united-states-decision-tosupport-temporary-waiver-on-intellectual-property-rights-for-covid-19-vaccines 
Thambisetty, McMahon, McDonagh, Kang, Dutfield
The TRIPS Intellectual Property

Waiver Proposal

to the proposal - focusing primarily on patent rights and trade secrets - which are most relevant to the present COVID-19 vaccine context. We explain why the existing TRIPS flexibilities around compulsory licensing are incapable of addressing the present pandemic context adequately, in terms of both procedure and legal substance..$^{10}$

The extent of the current health crisis posed by COVID-19 is as undeniable as the current global response is untenable. Given the ongoing absence of sufficient engagement by the pharmaceutical industry with proposed global mechanisms to share intellectual property rights, data and know-how to address the pandemic, we argue that mandatory mechanisms are needed. ${ }^{11}$ The TRIPS waiver is an essential legal instrument in this context for enabling a radical increase in manufacturing capacity, and hence supply, of COVID19 vaccines, creating a pathway to achieve global equitable access. ${ }^{12}$

We make two arguments to this effect: first, the TRIPS waiver is a necessary and proportionate legal measure for clearing intellectual property (IP) barriers in a direct, consistent and efficient fashion, enabling the freedom to operate for more companies to produce COVID-19 vaccines and other health technologies without the fear of infringing another party's IP rights and the attendant threat of litigation; and second, the TRIPS waiver acts as an important political, moral and economic lever towards encouraging solutions aimed at global equitable access to vaccines, which is in the wider interest of the global public.

It is not too late for these global solutions to be reached via voluntary agreements between states, the WHO, the WTO and pharmaceutical companies - whereby such companies could voluntarily agree to share IP, data and know-how and to transfer technology to enable a radical increase of manufacturing capacity for COVID-19 vaccines across the world. The WHO's Independent Panel for Pandemic Preparedness and Response recently recommended that the WTO and WHO convene a meeting of vaccineproducing countries and manufacturers to gain agreement on technology transfer and voluntary licensing arrangements for COVID-19 vaccines; and, that in the absence of such agreement within three months, the proposed TRIPS waiver should come into effect immediately. ${ }^{13}$ The waiver proposal, and the mounting support it is getting from civil society, notable public figures, and many countries, could indeed act as a strong lever to encourage greater co-operation by industry with such voluntary proposals. ${ }^{14}$ Nonetheless,

10 S Ragavan and A Vanni (Eds.), Intellectual Property Law and Access to Medicine: TRIPS Agreement, Health, and Pharmacenticals (Routledge, 2021). See also O Aginam, J Harrington and PK Yu (Eds.), The Global Governance of HIV/AIDS: Intellectual Property and Access to Essential Medicines (Edward Elgar, 2013).

11 Examples of these discussed below include the World Health Organization's proposed Covid-19 Technology Access Pool (C-TAP), which has attracted very limited industry engagement to date. See details at https://www.who.int/initiatives/covid-19-technology-access-pool

${ }_{12} \mathrm{M}$ Mazzucato, J Ghosh and E Torreele, 'To control the pandemic, it is essential to suspend intellectual property rights on medical products related to covid-19' The Economist (20 April 2021) https://www.economist.com/byinvitation/2021/04/20/mariana-mazzucato-jayati-ghosh-and-els-torreele-on-waiving-covid-patents

13 The Independent Panel, 'COVID-19: Make it the Last Pandemic' (May 2021) https://theindependentpanel.org/wp-content/uploads/2021/05/COVID-19-Make-it-the-Last-

Pandemic final.pdf at 14 .

${ }^{14}$ UNAIDS, 'Former heads of state and Nobel laureates call on President Biden to waive intellectual property rules for COVID vaccines' (14 April 2021) 
in the absence of sufficient co-operation at present, and as we continue to see a lack of adequate engagement by industry to enable the radical scale-up of manufacturing that is needed for COVID-19 vaccines, mandatory solutions must be advanced, and the waiver is a key part of this.

In making these arguments, we acknowledge and explain that the TRIPS waiver proposal is not a panacea for all the ills of global vaccine inequity. Nonetheless, we argue that in the current context the TRIPS waiver is a fundamental ingredient for facilitating global equitable access to COVID-19 vaccines, which is vital for bringing the pandemic to an end.

To argue against the TRIPS waiver at this time is to give tacit backing to the status quo, a system that is currently failing LMIC populations and is projected to continue failing them in the coming years. ${ }^{15}$ Since the present legal order, and the incentives embedded within it, support a system that prioritises vaccinating populations in HICs, it is only by fundamentally changing course that we can hope to have a realistic chance to make vaccines accessible to the entire global public in the short-term. ${ }^{16}$ In the medium to long term, the discussion generated by the TRIPS waiver has the potential to act as a catalyst towards a structural rebalancing of monopoly market power for pandemic situations and to encourage profound changes in global pharmaceutical production and capacity.

\section{INTELLECTUAL PROPERTY RIGHTS, COVID-19 AND GLOBAL VACCINE INEQUITY}

The case for making systemic changes to how intellectual property law incentivises health technologies is not new. The 2016 United Nations Secretary-General's report on access to medicines recognised disjunctures in law, policy and practice in relation to the right to health ${ }^{17}$ and international trade, especially with regard to conflicts between intellectual property rules and public health objectives. ${ }^{18}$ The COVID-19 pandemic has electrified this long-running debate over global access to health technologies by once again bringing into

https://www.unaids.org/en/resources/presscentre/featurestories/2021/april/20210414 letter-waiveintellectual-property-rules-COVID-vaccines

15 'Editorial: The World Needs Many More Coronavirus Vaccines' The New York Times (24 April 2021)

https://t.co/oKu2bNGU5H?amp=1. See also 'Vaccine Nationalism means that poor countries will be left behind' The Economist (January 2021) https://www.economist.com/graphic-detail/2021/01/28/vaccinenationalism-means-that-poor-countries-will-be-left-behind.

16 A Irwin, 'How Covid Spurred Africa to plot a Vaccines Revolution' Nature (21 April 2021) https://www.nature.com/articles/d41586-021-01048-1

17 The right to health is enshrined in several international legal instruments, see in particular: Universal Declaration of Human Rights (UDHR), Article 25 and International Covenant on Economic, Social and Cultural Rights, Article 12. See also D Matthews, 'The Right to Health and Patents' in C Geiger (Ed.), Research Handbook on Human Rights and Intellectual Property (Edward Elgar, 2015) 496-512.

18 Report of the United Nations Secretary-General's High-Level Panel on Access to Medicines: Promoting innovation and access to health technologies (September 2016) http://www.unsgaccessmeds.org/final-report/ 
Thambisetty, McMahon, McDonagh, Kang, Dutfield
The TRIPS Intellectual Property

Waiver Proposal

the open the problematic relationship between intellectual property law and global health. ${ }^{19}$

The pandemic has exacerbated existing global inequalities, none more apparent than in the case of vaccine production and distribution. As of 14 May 2021, the US and UK have vaccinated around half of their adult populations against COVID-19 with at least one vaccine dose. ${ }^{20}$ Israel has already exceeded this, vaccinating $63 \%$ of its citizens with one dose. ${ }^{21} \mathrm{EU}$ countries are catching up: the culminative uptake of one vaccine dose for adults over 18 in EU/EEA countries is currently 36\%.22 However, billions in Asia, Africa and Latin America remain unvaccinated, and crucially, many people in such countries have no hope of receiving a COVID-19 vaccine in 2021, 2022 or even $2023 .{ }^{23}$ At the time of writing, it is reported that just $1.39 \%$ of the total population in Africa, and $10.53 \%$ in India, have received at least one vaccine dose. ${ }^{24}$ Indeed, recent data highlights that 'only 0.3 percent of the vaccines administered globally have been given in the 29 poorest countries where 9 percent of the world's population lives'. ${ }^{25}$ It was predicted in late 2020 that $90 \%$ of those living in 67 low income countries would not obtain access to COVID-19 vaccines

${ }^{19}$ For a recent statement on the role of business entities to facilitate the right to health (and not to enforce IP in a manner inconsistent with this in the vaccine context) see Committee on Economic, Social and Cultural Rights, Statement on universal affordable vaccination for COVID-19, international cooperation and intellectual property E/C.12/2021/1. See also G Dutfield, That High Design of Purest Gold: A Critical History of the Pharmaceutical Industry, 1880-2020 (World Scientific Publishing, 2020); EFM 't Hoen, The Global Politics of Pharmacentical Monopoly Power: Drug Patents, Access, Innovation and the Application of the WTO Doba Declaration on TRIPS and Public Health (AMB Publishing, 2009); SF Halabi, Intellectual Property and the New International Economic Order: Oligopoly, Regulation, and Wealth Redistribution in the Global Knowledge Economy (chapter 6 on 'Access to medicines and vaccines') (Cambridge University Press, 2018); G Krikorian and A Kapczynski (Eds.), Access to Knowledge in the Age of Intellectual Property (Zone Press, 2010); S Ragavan and A Vanni (Eds.), Intellectual Property Law and Access to Medicine: TRIPS Agreement, Health, and Pharmaceuticals (Routledge, 2021).

20 On 14 May 2021, the US had vaccinated $46 \%$ of its adult population with one dose, while the UK had vaccinated $54 \%$ of its population with one dose https://ourworldindata.org/covid-vaccinations

${ }^{21}$ See details at https://ourworldindata.org/covid-vaccinations - figure reported 14 May 2021.

22 Figure reported on 17 May 2021 at https://vaccinetracker.ecdc.europa.eu/public/extensions/COVID$19 /$ vaccine-tracker.html\#uptake-tab

23 'Vaccine Nationalism means that poor countries will be left behind' The Economist (January 2021) https://www.economist.com/graphic-detail/2021/01/28/vaccine-nationalism-means-that-poor-countries-willbe-left-behind

24 These figures were reported on 19 May 2021 and represent the: 'Share of the total population that received at least one vaccine dose. This may not equal the share that are fully vaccinated if the vaccine requires two doses.' See details at https://ourworldindata.org/covid-vaccinations

${ }^{25}$ EFM 't Hoen, 'Covid shows the world it needs new rules to deal with pandemics' Medicines Law and Policy (21 May 2021) https://medicineslawandpolicy.org/2021/05/covid-shows-the-world-it-needs-new-rules-to-deal-withpandemics/. See also J Holder, 'Tracking Coronavirus Vaccinations Around the World' The New York Times (21 May 2021) https://www.nytimes.com/interactive/2021/world/covid-vaccinationstracker.html?action $=$ click\&module $=$ RelatedLinks\&pgtype=Article. See also B Mueller, 'While rich countries come back to life, the virus is ravaging poorer nations' The New York Times (5 May 2021) https://www.nytimes.com/2021/05/05/world/while-rich-countries-come-back-to-life-the-virus-is-ravagingpoorer-nations.html 
in $2021 ; 26$ yet, with the ongoing substantial under-delivery of promised vaccines, ${ }^{27}$ and problems with supply chains, it is likely that even this is an overestimate. ${ }^{28}$

Against the backdrop of emerging vaccine inequity, WHO Director-General Dr Tedros Adhanom Ghebreyesus, speaking in January 2021, lamented that: ' $\ldots$ the world is on the brink of a catastrophic moral failure - and the price of this failure will be paid with lives and livelihoods in the world's poorest countries'. ${ }^{29}$ Although the WHO guidelines recommend that health workers and high-risk people in all nations should get vaccinated first, ${ }^{30}$ HICs, including the US, UK and EU states, have not followed through, instead prioritising their own populations. ${ }^{31}$

Aside from the moral failure this inequity is creating, there is also the pragmatic reality: we need global equitable access to vaccines to bring COVID-19 under control. Without a significant and rapid increase of vaccine production and equitable global distribution, new variants of the virus will likely continue to emerge. ${ }^{32}$ Although there is, as yet, no scientific consensus on the effect on vaccine efficacy of new variants, ${ }^{33}$ it is thought that such variants may render existing vaccines less effective, or ineffective, so that it may be necessary to modify vaccines to work against new variant strains. ${ }^{34}$ In effect, '[v]accine nationalism is not just morally indefensible. It is epidemiologically self-defeating and

26 Oxfam, 'Campaigners warn that 9 out of 10 people in poor countries are set to miss out on covid-19 vaccine next year' (9 Dec 2020) https://www.oxfam.org/en/press-releases/campaigners-warn-9-out-10-people-poorcountries-are-set-miss-out-covid-19-vaccine; O Dyer, 'Covid-19: Many poor countries will see almost no vaccine next year, aid groups warn' 371 BMJ (2020) - doi:10.1136/bmj.m4809; See also A Karan and T Pogge, 'Solving global vaccine inequity requires new incentives for pharmaceutical companies' BMJ Blog (2 April 2021) https://blogs.bmj.com/bmj/2021/04/02/solving-global-vaccine-inequity-requires-new-incentives-forpharmaceutical-companies/

${ }_{27}$ Z Rizvi, 'Not Enough: Six Reasons Why COVID-19 Vaccine Manufacturing Must be Rapidly Scaled-Up’ Public Citizen (13 May 2021) https://www.citizen.org/article/not-enough-six-reasons-why-covid-19-vaccinemanufacturing-must-be-rapidly-scaled-up/\# ftn3

28 'India's Serum Institute to start export of COVID-19 vaccine by year-end' Reuters (18 May 2021) https://www.reuters.com/world/india/indias-serum-institute-start-export-covid-19-vaccine-by-year-end-2021$\underline{05-18 /}$

${ }_{29}$ WHO Director-General's opening remarks at 148th session of the Executive Board (18 January 2021) https://www.who.int/director-general/speeches/detail/who-director-general-s-opening-remarks-at-148thsession-of-the-executive-board

30 WHO, 'Roadmap for Prioritizing Population Groups for Vaccines Against Covid-19' (27 September 2020) https://www.who.int/immunization/sage/meetings/2020/october/Session03 Roadmap Prioritization Covid -19 vaccine.pdf

31 G Yamey, 'Could an act of global solidarity persuade rich nations that vaccine nationalism is misguided' (7 Dec 2020) https:// covid19healthdiaries.com/diary?did $=397$

32 Wouters et al. remark: 'More equitable distribution of COVID-19 vaccines would help contain the pandemic sooner, and thus minimise the risk of new variants of the virus arising, against which existing vaccines might be less effective.' OJ Wouters, KC Shadlen, M Salcher-Konrad, AJ Pollard, HJ Larson, Y Teerawattananon and M Jit, 'Challenges in ensuring global access to COVID-19 vaccines: production, affordability, allocation, and deployment' 397 Lancet (2021) https://www.thelancet.com/journals/lancet/article/PIIS0140-6736(21)00306-

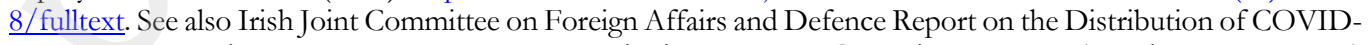
19 Vaccines to Developing Countries (March 2021) https://data.oireachtas.ie/ie/oireachtas/committee/dail/33/joint committee on foreign affairs and defence Lreports/2021/2021-03-05 report-on-the-distribution-of-covid-19-vaccines-to-developing-countries en.pdf.

33 'Top Scientists Question the Need for Covid-19 Booster Shots' Reuters (13 May 2021) https://www.reuters.com/world/middle-east/top-scientists-question-need-covid-19-booster-shots-2021-05$\underline{13 /}$

$34 \mathrm{~N}$ Triggle, 'Covid: Scientists developing vaccine boosters to tackle variants' $B B C$ (8 Feb 2021) https://www.bbc.com/news/uk-55976037 
Thambisetty, McMahon, McDonagh, Kang, Dutfield
The TRIPS Intellectual Property

Waiver Proposal

clinically counterproductive'. 35 The lack of vaccine access in any one state, or group of states, threatens the control of COVID-19 everywhere (a point we return to below).

At present, limited production is creating problems of scarcity and unequal supply. ${ }^{36}$ This is despite some voluntary co-operation by industry, whereby some pharmaceutical companies are working together to boost production. For example, there is an agreement between Johnson \& Johnson (J\&J) and Merck to boost US production of the J\&J vaccine, ${ }^{37}$ which the US government helped to forge and for which it provided significant funding. ${ }^{38}$ Other voluntary arrangements include AstraZeneca's deals with Serum Institute of India (SII), ${ }^{39}$ and Fiocruz in Brazil, ${ }^{40}$ and the recent announcement of BioNTech's joint venture with Fosun Pharmaceuticals in China (which is separate from BioNTech's existing agreement with Pfizer). ${ }^{41}$ These arrangements are certainly very positive; indeed, we favour the creation of further voluntary licensing arrangements for COVID-19, and we support governments' attempts to establish these. However, such efforts to date simply remain grossly inadequate to meet the world's needs in the pandemic context. ${ }^{42}$

There must also be greater scrutiny of vaccine nationalism in the approaches of individual states, and a renewed focus on the sharing of vaccine surpluses between states to address the current vaccine inequity. We note that even where surplus supplies of vaccines have existed in some countries, such as in the US, these were prevented from being exported until very recently, through domestic prioritisation enforced by the US Defense Production Act (or were belatedly 'loaned' to neighbouring countries, such as Mexico and Canada). ${ }^{43}$

35 TA Ghebreyesus, 'Vaccine Nationalism Harms Everyone and Protects No One' Foreign Policy (2 February 2021) https://foreignpolicy.com/2021/02/02/vaccine-nationalism-harms-everyone-and-protects-no-one/

36 M Gaviria and B Kilic, 'BioNTech and Pfizer's BNT162 Vaccine Patent Landscape' Public Citizen (16 Nov 2020) https://www.citizen.org/article/biontech-and-pfizers-bnt162-vaccine-patent-landscape/ - ftnref3 (accessed 24th May 2021).

37 Merck, 'Why we're excited to partner on Johnson \& Johnson's COVID-19 vaccine' (10 March 2021) https://www.merck.com/stories/why-were-excited-to-partner-on-johnson-and-johnsons-covid-19-vaccine/

38 'Biden Administration Announces Historic Manufacturing Collaboration Between Merck and Johnson \& Johnson to Expand Production of COVID-19 Vaccines' (2 March 2021) https://www.hhs.gov/about/news/2021/03/02/biden-administration-announces-historic-manufacturingcollaboration-between-merck-johnson-johnson-expand-production-covid-19-vaccines.html

39 'Serum Institute of India obtains emergency use authorisation in India for AstraZeneca's COVID-19 vaccine' January 2021) https://www.astrazeneca.com/media-centre/press-releases/2021/serum-institute-of-indiaobtains-emergency-use-authorisation-in-india-for-astrazenecas-covid-19-vaccine.html

${ }_{40}$ 'MSF welcomes Fiocruz's step towards transparency of AstraZeneca deal' (November 2020) https://msfaccess.org/msf-welcomes-fiocruzs-step-towards-transparency-astrazeneca-deal

41 A Liu, 'BioNTech, Fosun Pharma eye 1B doses of COVID-19 vaccine capacity with new China JV' Fierce Pharma (10 May 2021) https://www.fiercepharma.com/manufacturing/biontech-fosun-pharma-eye-1b-doses-covid-19vaccine-capacity-new-china-jv

42 It has been reported that the current manufacturing capacity for such vaccines globally stands at enough for 3.5 billion doses but at least 11 billion will be needed to vaccine $70 \%$ of the total global population - see EFM 't Hoen, 'Covid shows the world it needs new rules to deal with pandemics' Medicines Law and Policy (21 May 2021) https://medicineslawandpolicy.org/2021/05/covid-shows-the-world-it-needs-new-rules-to-deal-withpandemics/

${ }^{43}$ L Fedor, 'US to share at least 20m more Covid vaccines with other countries' Financial Times (17 May 2021) https://www.ft.com/content/3455a8e6-d232-4d5e-a0e1-140db03c8dcc; 'US Loans Vaccines To Mexico, Canada' NPR (23 March 2021) https://www.npr.org/2021/03/23/980449330/us-loans-vaccines-to-mexicocanada?t=1621319881761 
Very little production of COVID-19 vaccines is occurring in Africa, and production in South America lags well behind that of the US and Europe. ${ }^{44}$ Furthermore, as we explain below, relying heavily on a single producer - the Serum Institute of India (SII) - to provide for the international voluntary COVID-19 Vaccines Global Access (COVAX) programme led by WHO, CEPI and Gavi, has proven acutely inadequate to date. ${ }^{45}$ At the time of writing, given the current devastating COVID-19 crisis in India, the SII is banned from exporting any doses for the COVAX scheme, to concentrate on meeting the needs in India. ${ }^{46} \mathrm{~A}$ recent SII statement suggests it hopes 'to start delivering to COVAX and other countries by the end of the year' but this cannot be guaranteed. ${ }^{47}$ The short-term and medium-term risks to developing countries of the status quo continuing are incalculable, as shown by the present devastating crises in India, Nepal and Brazil. ${ }^{48}$

\section{THE CURRENT COVID-19 VACCINE MARKET - ANALYSING INCENTIVES AND OUTLINING THE PROBLEMS OF PRICING AND SUPPLY}

The international and territorial patent system is often justified as a means to an end, providing incentives/rewards for risky and expensive research and development (R\&D) spending, for the greater aim of creating public goods. ${ }^{49}$ The theoretical idea of 'incentive' or 'promotion' is captured in the architecture of the international patent legislation as embodied by TRIPS. ${ }^{50}$ Yet the 'incentive to invent' argument is usually framed in the context of a single legal system with a level of social, technical and economic development that can respond to such incentives. ${ }^{51}$ As we explore later on in this paper, the concept of

44 'Editorial: The World Needs Many More Coronavirus Vaccines' The New York Times (24 April 2021) https://www.nytimes.com/2021/04/24/opinion/covid-vaccines-poor-countries.html

45 'WHO urges countries to donate COVID-19 vaccines as supplies tighten' Reuters (27 March 2021) https://www.reuters.com/business/healthcare-pharmaceuticals/who-urges-countries-donate-10-mln-dosescovid-19-vaccines-poorest-2021-03-26/

${ }^{46}$ S Findlay, M Peel and DP Mancini, 'India's block on vaccine exports deals blow to dozens of nations' The Irish Times (26 March 2021) https://www.irishtimes.com/news/world/asia-pacific/india-s-block-on-vaccine-exportsdeals-blow-to-dozens-of-nations-1.4520812

${ }_{47}$ S Findlay and D Pilling, 'Indian vaccine maker extends freeze on export of Covid jabs' Financial Times (18 May 2021) https://www.ft.com/content/63fbbb79-f657-4e6c-b190-cffd0d630593; See official Serum Institute of India public statement posted to social media on 18 May 2021 https://twitter.com/SerumInstIndia/status/1394652001573629958/photo/1

${ }_{48} \mathrm{P}$ Beaumont, 'Why India's worsening Covid crisis is a dire problem for the world' The Guardian (25 April 2021) https://www.theguardian.com/world/2021/apr/25/the-world-must-act-indias-covid-crisis-is-a-dire-problemfor-us-all; See also M Davey, 'Children with Covid: why are some countries seeing more cases - and deaths?' The Guardian (23 May 2021) https://www.theguardian.com/world/2021/may/23/children-with-covid-why-aresome-countries-seeing-more-cases-and-deaths

${ }^{49}$ L McDonagh, European Patent Litigation in the Shadow of the Unified Patent Court (Edward Elgar, 2016), 1-10.

50 TRIPS Art. 7: Objectives 'The promotion and enforcement of intellectual property rights should contribute to the promotion of technological innovation and to the transfer and dissemination of technology, to the mutual advantage of producers and users of technological knowledge and in a manner conducive to social and economic welfare, and to a balance of rights and obligations.'

${ }^{51}$ S Sell, Power and Ideas: North-South politics of Intellectual Property and Antitrust (State University of New York Press, 1997). 
Thambisetty, McMahon, McDonagh, Kang, Dutfield
The TRIPS Intellectual Property

Waiver Proposal

'incentive' within the international IP context underpinned by TRIPS is contestable, particularly in the light of varying levels of development in different states. The incentive justification can also become very muddled when 'invention' is equated erroneously with 'innovation' 52 or when it does not take sufficient account of industry-specific contexts. ${ }^{53}$

Even if we proceed on the basis that that patent law does create at least some incentives, ${ }^{54}$ as scholars our duty is to interrogate and analyse these incentives and their effects. We must ask the following question: what specific practices is the patent system incentivising?

A patent creates a legal monopoly right in the use of the patented invention for 20 years. It is, therefore, a restrictive right by definition, with the rationale of disabling competition temporarily. It is designed to bestow the holder with an exclusive right to an invention's commodification and to give the holder a head-start for securing dominant market share. As a position of dominance becomes more secure, enabled by patent strategies and doctrine, incentives to share the technology may dissipate. Patent owners have the power to artificially restrict the production of the patented good for strategic reasons, for as long as legally possible. ${ }^{55}$ The monopoly right also enables the patent holder to exercise unfettered pricing power within a market. The trouble is that monopoly market power in the pharmaceutical industry has huge consequences for the public, unlike market domination in, say, mousetraps. ${ }^{56}$ Thus, patent law is fundamental to the way the pharmaceutical market is constructed; and as such, patent law must be considered a key factor when the market produces dysfunctional or inequitable results, as it is doing now during the COVID-19 crisis. $^{57}$

52 S Thambisetty, ‘Why Patent Law Doesn’t Do Innovation Policy’ LSE Legal Studies Working Paper No. 20/2013 https://ssrn.com/abstract=2328173; See also JA Schumpeter, Business Cycles $-A$ Theoretical, Historical and Statistical Analysis of the Capitalist Process (McGraw-Hill Book Company, 1939) 85.

${ }^{53}$ DL Burk and M Lemley, 'Policy Levers in Patent Law' 89 Virginia Law Review (2003) 1575.

${ }^{54}$ In this respect, we do not concede the wider point - indeed, we critique the core assumptions of the incentive narrative further below. For a critical analysis of patent law's underlying justification and patent value, see HY Kang, 'Patents as Assets: Intellectual Property Rights as Market Subjects and Objects' in K Birch and F Muniesa (Eds.), Assetization: Turning Things into Assets in Technoscientific Capitalism (MIT Press, 2020): '...the often voiced criticisms against patents, such as excluding production and labour from ownership, limiting access to patented inventions, exclusionary practices and unfettered pricing, are not novel. Patents are monopoly rights that have been created to legally sanction such practices and effects. These criticisms nonetheless raise serious doubts about the patent law system's underlying justification.' For a critique of the inventive labour/incentive argument in patent justification, see HY Kang, 'Patents as Credit - When Intellectual Property Becomes Speculative' 194 Radical Pbilosopby (2015) 29, at 30-31.

${ }^{55}$ S Thambisetty, 'Vaccines and Patents: How Self-Interest and Artificial Scarcity Weaken Human Solidarity' LSE Covid-19 blog (March 2021) https://blogs.lse.ac.uk/covid19/2021/02/11/vaccines-and-patents-how-selfinterest-and-artificial-scarcity-weaken-human-solidarity/; For a discussion of the broader 'governance' functions patents bestow on rights-holders, see A McMahon, 'Biotechnology, Health and Patents as Private Governance Tools: The Good, the Bad and the Potential for Ugly?' Intellectual Property Quarterly (2020) 161.

${ }^{56}$ G Dutfield, That High Design of Purest Gold: A Critical History of the Pharmacentical Industry, 1880-2020 (World Scientific Publishing, 2020); See also TT Arvind \& A McMahon, 'Commodification, control, and the contractualisation of the human body' in E Bertrand, M-X Catto, A Mornington (Eds.), The Limits of the Market: Commodification of nature and body (Mare \& Martin, 2020).

57 D Matthews, 'Patenting Strategies and Competition Law in the Pharmaceutical Sector: Implications for Access to Medicines' 38 European Review of Intellectual Property (2016) 661. 
Inequities affecting the global public are all the more glaring given that during the pandemic unprecedented amounts of public funding have gone into vaccine research, with several vaccines relying on major breakthroughs that occurred at universities and public institutions (including the University of Pennsylvania (Penn), Oxford University, and the US National Institutes of Health (NIH)). ${ }^{8}$ According to a recent medRxiv preprint, 'public funding accounted for $97.1-99.0 \%$ of the funding towards the R\&D of ChAdOx and the Oxford-AstraZeneca vaccine'. ${ }^{59}$ In January 2021 it was reported that the global public sector had spent at least $€ 93$ billion on the development of COVID-19 vaccines and therapeutics $-€ 85.6$ billion of this on vaccines. ${ }^{60}$

The inequities of vaccine production and distribution are related to concerns over pricing and the profit incentive. ${ }^{61}$ The present IP system allows for monopoly power in pricing, and Stoller suggests this potentially results in a perverse incentive for COVID-19 vaccine manufacturers, one that does not necessarily favour achieving global equitable access to vaccines. ${ }^{62}$ From a purely financial perspective, the ongoing global pandemic offers considerable pecuniary incentives for companies making vaccines and their shareholders. ${ }^{63}$ The profit incentive and financial interests may clash with what is required to achieve the goal of bringing the pandemic to an end globally as soon as possible. ${ }^{64}$ As COVID-19 moves gradually from a 'pandemic' to 'endemic' scenario in $\mathrm{HICs},{ }^{65}$ a private market that seeks profit maximisation will likely incentivise and prioritise production of expensive vaccine booster doses for HICs (where these are needed) over first doses for

58 See e.g., Oxford University's patent application on the adenoviral vector (EP3475433A1), intention to grant communicated on $10 \quad$ March 2021 : https://worldwide.espacenet.com/patent/search/family/056891578/publication/EP3475433A1?q=EP347543 3A1. For background, see L McDonagh, 'Could university patents stand in the way of universal global access to a COVID-19 vaccine?’ LSE Covid-19 blog (10 September 2020). https://blogs.lse.ac.uk/covid19/2020/09/10/could-university-patents-stand-in-the-way-of-universal-globalaccess-to-a-covid-19-vaccine/

59 S Cross, Y Rho, H Reddy, T Pepperrell, F Rodgers, R Osborne, A Eni-Olotu, R Banerjee, S Wimmer and S Keestra, 'Who funded the research behind the Oxford-AstraZeneca COVID-19 vaccine? Approximating the funding to the University of Oxford for the research and development of the ChAdOx vaccine technology' medRxiv (2021) preprint doi: https://doi.org/10.1101/2021.04.08.21255103 - this version posted 10 April 2021. NB: ChAdOx refers to the specific viral vector technology developed at Oxford.

${ }^{60}$ An estimated $71 \%$ of this funding went to SMEs - 'Governments Spent at Least $€ 93$ bn on COVID-19 Vaccines and Therapeutics During the Last 11 Months' Business Wire (11 Jan 2021) https://www.businesswire.com/news/home/20210110005098/en; M Hoecklin, '€93 Billion Spent By Public Sector On COVID Vaccines and Therapeutics in 11 Months, Research Finds' Health Policy Watch (12th January 2021)https://healthpolicy-watch.news/81038-2/

61 J Kollewe, 'From Pfizer to Moderna: who's making billions from Covid-19 vaccines?' The Guardian (6 March 2021)https://www.theguardian.com/business/2021/mar/06/from-pfizer-to-moderna-whos-making-billionsfrom-covid-vaccines

62 M Stoller, 'Why Joe Biden Punched Big Pharma in the Nose Over Covid Vaccines' Substack (2021) https://mattstoller.substack.com/p/why-joe-biden-punched-big-pharma

63 'Pfizer's boss thinks Covid-19 is reshaping Big Pharma for the better' The Economist (10 April 2021) https://www.economist.com/business/2021/04/10/pfizers-boss-thinks-covid-19-is-reshaping-big-pharmafor-the-better

${ }^{64}$ P Patnaik \& HY Kang, 'India: The Quagmire for COVAX; Q\&A: Hyo Yoon Kang on the financialization of intellectual property \& COVID-19’ (20 April 2021) https://genevahealthfiles.substack.com/p/indiathe-quagmire-for-covax-q-and

$65 \mathrm{~N}$ Phillips, 'The coronavirus is here to stay — here's what that means' Nature (16 February 2021) https://www.nature.com/articles/d41586-021-00396-2 
Thambisetty, McMahon, McDonagh, Kang, Dutfield
The TRIPS Intellectual Property

Waiver Proposal

LMICs. ${ }^{66}$ 'The expected need for 'booster' doses to address new variants of COVID-19 will put further pressure on the already limited supplies of vaccines and existing manufacturing capacities.

Although research suggests that the unit cost of production of a mRNA vaccine dose is less than US\$3, Pfizer prices it at US\$19.50.67 Claiming that this is 'pandemic pricing' and yielding around 20\% gross profit margin, Pfizer states that in a non-pandemic environment it would be normally priced between US\$150 and US\$175, with further potential to significantly improve profit margin due to lower cost per unit with rising volume of production. ${ }^{68}$ Even with the current price of less than US\$20, Pfizer is expected to generate US\$26 billion in vaccine revenue in 2021.69

Furthermore, although AZ has stated that it will supply vaccines 'at cost' so long as the pandemic is ongoing, its Memorandum of Understanding with Brazilian manufacturer, Fiocruz, reveals that $A Z$ reserves the right to declare an end to the pandemic as soon as July $2021 .{ }^{70}$ There is evidence of LMICs being charged a higher price than HICs. ${ }^{71}$ For instance, AstraZeneca (AZ) reportedly charged South Africa more than double (US\$5.25) the price per dose that it charged EU countries (US\$2.16)..$^{72}$ Similar inequities have been observed in vaccine procurement deals with Uganda and Bangladesh. ${ }^{73}$ Even within India, pricing of the Oxford/AZ vaccine by the SII has not been equitable. ${ }^{74}$ Professor Louise Richardson, Vice-Chancellor of the University of Oxford, defends the Oxford/AZ approach, ${ }^{75}$ noting that, unlike AZ, several other pharmaceutical companies 'have derived

${ }^{66} \mathrm{~N}$ Triggle, 'UK orders another 60m from Pfizer' BBC (28 April 2021) https://www.bbc.co.uk/news/uk$\underline{56921018}$

${ }_{67}$ Z Kis, C Kontoravdi, R Shattock and N Shah, 'Resources, Production Scales and Time Required for Producing RNA Vaccines for the Global Pandemic Demand' Vaccines 2021, 9, 3. https://doi.org/10.3390/vaccines9010003

68 Pfizer, Edited Transcript, Q4 2020 Earnings Call (2 February 2021) https://s21.q4cdn.com/317678438/files/doc financials/2020/q4/PFE-USQ Transcript 2021-02-02.pdf

${ }^{69}$ Pfizer Vaccine revenue is projected to hit $\$ 26 \mathrm{bn}$ in 2021 with production surge' The Washington Post (4 May 2021) https://www.washingtonpost.com/business/2021/05/04/pfizer-covid-vaccine-revenue/

${ }_{70}$ DP Mancini, 'AstraZeneca vaccine document shows limit of no-profit pledge' Financial Times (7 October 2020) https://www.ft.com/content/c474f9e1-8807-4e57-9c79-6f4af145b686

71 O Dwyer, 'Covid-19: Countries are learning what others paid for vaccines' BMJ (2021) 372 https://www.bmi.com/content/372/bmi.n281

${ }^{72} \mathrm{H}$ Sullivan, 'South Africa paying more than double EU price for Oxford vaccine' The Guardian (22 Jan 2021) https://www.theguardian.com/world/2021/jan/22/south-africa-paying-more-than-double-eu-price-foroxford-astrazeneca-vaccine

${ }^{73} \mathrm{C}$ Paun and A Furlong, 'Poorer countries hit with higher price tag for Oxford/AstraZeneca vaccine' Politico (22 February 2021) https://www.politico.eu/article/astrazeneca-vaccine-cost-higher-in-poorer-countriescoronavirus/

74 D Dodd, 'India's vaccine price move fuels criticism of pandemic strategy' Financial Times (26 April 2021) https://www.ft.com/content/f257992c-7002-46b0-8d4e-7e2333442efc

75 Oxford initially contemplated licensing the relevant IP and know-how openly, so that any viable producer could manufacture the vaccine but instead agreed an exclusive licence with AZ. McDonagh remarks:

'Credit where it is due: Oxford and AZ have acted more ethically than other providers such as Moderna and BioNTech/Pfizer. The Oxford-AZ deal includes the potential for non-exclusive, royalty-free licences to be offered to manufacturers to support production that is free-of-charge, at-cost, or at cost with limited margin supply. A bilateral licensing deal is in effect between Oxford/AZ and the Serum Institute India (SII). However, bilateral agreements, while positive, are ultimately limited in their scope ... Recent supply problems 
enormous profits from the pandemic'. ${ }^{76}$ Notably, however, the financial markets are beginning to price in the technological and IP advantages obtained by AZ and Oxford. ${ }^{77}$ AZ has enhanced its future prospects and share value, made clear by its recent award of US $\$ 3.6$ billion in dividends. ${ }^{78}$ In April 2021, the Oxford University spin-off company that helped develop the vaccine - Vaccitech - filed its Initial Public Offering (IPO) on the US Nasdaq exchange, raising more than US $\$ 100$ million. ${ }^{79}$

Even if we assume that all companies will focus on developing first doses for LMICs - and this cannot be taken for granted - the potential need for booster doses could split current manufacturing capacity, dividing it between (HICs') vaccine boosters and (LMICs') first doses, thereby likely maintaining, or even increasing, the current vaccine access gap. In short, the current (largely unregulated) power of vaccine makers to decide when and where to produce, to decide price, and to define when the current crisis will have abated for pricing purposes, is not likely to create the right incentives to boost global production sufficiently to resolve existing vaccine inequities.

\section{FRAMING INTELLECTUAL PROPERTY IN THE CONTEXT OF THE INTERNATIONAL COVID-19 PANDEMIC RESPONSE: C-TAP, COVAX AND THE TRIPS WAIVER PROPOSAL}

Aside from the current TRIPS waiver proposal, which we discuss in detail further in the next section, there are two existing, relevant and significant World Health Organization (WHO) global initiatives for pandemic response - the COVID-19 Technology Access Pool (C-TAP) and COVAX - and each incorporates different approaches and understandings of the role of IP and knowledge sharing in the fight against COVID-19.80

arising from AZ's failure to meet its production targets led AZ to seek to import to the UK millions of vaccine doses made in India at SII. Were it not for AZ's UK and European production shortfalls, these doses would, presumably, have been made available to developing countries (via COVAX). The idea that AZ would attempt to prioritise UK supply needs over those of developing countries calls into question the ultimate value of the agreement between AZ and SII.'

L McDonagh, 'Oxford University has a special duty to ensure jabs reach the Global South' LSE Covid-19 blog (April 2021) https://blogs.lse.ac.uk/covid19/2021/04/28/oxford-university-has-a-special-responsibility-toensure-jabs-reach-the-global-south/

${ }_{76}$ L Richardson, 'Time for other vaccine makers to follow Oxford/AstraZeneca's lead' Financial Times (18 May 2021) https://www.ft.com/content/65856fab-e394-4407-adf9-63edd8acdad3

${ }^{77} \mathrm{~L}$ McDonagh, 'Oxford University has a special duty to ensure jabs reach the Global South' LSE Covid-19 blog (April 2021) https://blogs.lse.ac.uk/covid19/2021/04/28/oxford-university-has-a-special-responsibility-toensure-jabs-reach-the-global-south/

78 S Boseley, 'Campaign to waive Covid jab patent highlights \$26bn shareholder payouts' The Guardian (22 April 2021) https://www.theguardian.com/world/2021/apr/22/campaign-to-waive-covid-jab-patent-highlights26bn-shareholder-payouts

79 A Keown, 'AstraZeneca Vaccine Collaborator Vaccitech Snares \$110.5 Million IPO’ Biospace (30 April 2021) https://www.biospace.com/article/vaccitech-raises-110-5-million-in-ipo/

${ }^{80}$ For a detailed discussion of the various current global mechanisms for global equitable access to COVID-19 vaccines, see S Geiger \& A McMahon, 'Too many Cooks or Too Many Recipes? An analysis of the institutional 
Thambisetty, McMahon, McDonagh, Kang, Dutfield
The TRIPS Intellectual Property

Waiver Proposal

As we outline here, these initiatives have not (at the time of writing) succeeded in ensuring global vaccine access. It is these failings and, in particular, the lack of industry engagement/co-operation with voluntary systems like the C-TAP, that have necessitated the TRIPS waiver proposal. ${ }^{81}$

\section{C-TAP AND COVAX}

The C-TAP scheme can be traced to Costa Rica's call for a voluntary pool of IP, data and know-how etc. in March 2020.82 In response to this, the WHO in partnership with the Government of Costa Rica launched C-TAP in May 2020 as an internationally coordinated mechanism of voluntary sharing of IP, data and know-how etc. in the fight against COVID-19.83 C-TAP is based on the model of the UN-backed Medicines Patent Pool (which is also an implementing partner of C-TAP) that aims to provide equitable access to HIV medication and treatment, and for other conditions. ${ }^{84}$ Yet, to date, the pharmaceutical industry has largely ignored C-TAP; it has not received formal cooperation from vaccine rights-holders. ${ }^{85}$

The other major international response is the COVAX scheme, launched in April 2020 by the WHO. Standing in contrast to C-TAP, COVAX operates as a public-private initiative, supported by HICs, the UN, CEPI and the Gates Foundation. ${ }^{86}$ COVAX is arguably designed to meet immediate, rather than systemic needs ${ }^{87}$ - it is a global mechanism whereby states can come together to purchase vaccines. This scheme comprises self-financing and also funded countries, including 92 LMICs. 88

COVAX is far from flawless - it has several problematic governance issues. ${ }^{89}$ Nevertheless, COVAX has achieved some successes in delivering some vaccines to LMICs. Nonetheless, optimistically, if it attains the current prediction COVAX will have distributed approximately 1.8 billion doses of vaccines to 92 participating LMICs by the

landscape and proliferation of proposals for Global Vaccine Equity for COVID-19' UCD Geary Institute Working Paper 8/21 (2021).

https://ideas.repec.org/p/ucd/wpaper/202108.html

81 This is correct as of 19 May 2021

82 E Silverman, 'WHO is asked to create a voluntary intellectual property pool to develop Covid-19 products' Stat News (24 March 2020) https://www.statnews.com/pharmalot/2020/03/24/covid19-coronavirus-costa-ricaintellectual-property/

${ }^{83}$ See details at https://www.who.int/initiatives/covid-19-technology-access-pool

${ }^{84}$ See details at https://medicinespatentpool.org/

${ }^{85}$ EFM 't Hoen, 'The elephant in the room at the WHO Executive Board' Medicines Law and Policy (22 January 2021) https://medicineslawandpolicy.org/2021/01/the-elephant-in-the-room-at-the-who-executive-board/

${ }_{86}$ See details at https://www.gavi.org/gavi-covax-amc-launch-event-april-2021

${ }^{87}$ S Geiger \& A McMahon, 'Too many Cooks or Too Many Recipes? An analysis of the institutional landscape and proliferation of proposals for Global Vaccine Equity Access for COVID-19' UCD Geary Institute Working Paper 8/21 (2021). See also K Walsh, A Wallace, M Pavis, N Olszowy, J Griffin and N Hawkins, 'Intellectual Property Rights and Access in Crisis' 52 IIC (2021) 379.

88 See details at https://www.gavi.org/vaccineswork/covax-explained

89 P Patnaik, 'Gavi \& Civil Society: Unhappy Engagement' Geneva Health Files Newsletter 4 (24 Sep 2020). See also J Ravelo, 'Is Covax Part of the Problem or the Solution?' Devex (11 March 2021) https://www.devex.com/news/iscovax-part-of-the-problem-or-the-solution-99334 
end of 2021 - covering just over one-fifth of their populations. ${ }^{90}$ This would, of course, be very welcome; but it falls significantly short of the needed population coverage, thereby failing to limit the risks of new variants arising, prolonging the pandemic. ${ }^{91}$ However, there are cogent reasons to be pessimistic about achieving even this moderate goal. The COVAX system continues to underdeliver vaccines, failing to meet stated targets, due both to vaccine nationalism in HICs and to the absolute lack of vaccines worldwide. Such issues will likely be heightened in coming months, without action, because, as noted, the devastating second wave of COVID-19 in India has led the government there to prevent the Serum Institute of India (the key vaccine manufacturer supplying to COVAX ${ }^{92}$ ) from supplying exports, instead focusing on the public health need in India. ${ }^{93}$ In March 2021, Dr Tedros Adhanom Ghebreyesus (DG WHO) stated that:

COVAX is ready to deliver, but we can't deliver vaccines we don't have. As you know, bilateral deals, export bans, vaccine nationalism and vaccine diplomacy have caused distortions in the market, with gross inequities in supply and demand. ${ }^{94}$

While systems like COVAX have a role to play to meet short-term needs, a model based on philanthropy and charity will not build sustainable medium- or long-term solutions. COVAX does not address productive or innovative capacities in the countries that most rely on it. Nor can so-called geopolitical 'vaccine diplomacy' suffice to ensure equitable vaccine access. For example, until the recent prevention of exports, India was using vaccine diplomacy as a geopolitical gambit, reportedly supplying 64.5 million doses to 85 different countries. ${ }^{95}$ Such endeavours may have positive effects globally but are ultimately inadequate.

\section{THE TRIPS WAIVER}

As noted above, the WHO's C-TAP scheme has not, to date, been supported by industry (and there are also concerns about a lack of support for a similar vehicle, the

90 The Independent Panel for Pandemic Preparedness and Response, Access to Vaccines, Therapeutics and Diagnostics: Background Paper 5 (May 2021) 1-7 https://theindependentpanel.org/wpcontent/uploads/2021/05/Background-paper-5-Access-to-vaccines-Therapeutics-and-Diagnostics.pdf

91 Ibid, 7

${ }^{92} \mathrm{WHO}$, 'COVAX reaches over 100 economies, 42 days after first international delivery' (8 April 2021) https://www.who.int/news/item/08-04-2021-covax-reaches-over-100-economies-42-days-after-firstinternational-delivery

${ }_{93}$ M Safi and A Kirk, 'Revealed: big shortfall in Covax Covid vaccine-sharing scheme' (22 April 2021) https://www.theguardian.com/world/2021/apr/22/revealed-big-shortfall-in-covax-covid-vaccine-sharingscheme; See also SII public statement extending the suspension of delivery at https://twitter.com/SerumInstIndia/status/1394652001573629958/photo/1

${ }_{94}$ World Health Organization (WHO), 'WHO Director-General's opening remarks at the media briefing on COVID-19’ (26 March 2021) https://www.who.int/director-general/speeches/detail/who-director-general-sopening-remarks-at-the-media-briefing-on-covid-19-26-march-2021

95 'Covid Diplomacy: How Indian's “Vaccine Maitry" Jabs have put China on the Ropes' (26 Jan 2021) https://www.news18.com/news/india/covid-diplomacy-how-indias-vaccine-maitri-jabs-have-put-china-onthe-ropes-3339179.html 
Thambisetty, McMahon, McDonagh, Kang, Dutfield
The TRIPS Intellectual Property

Waiver Proposal

mRNA Vaccine Transfer Hub facility). ${ }^{96}$ Meanwhile, COVAX has fallen considerably short of LMICs' needs. Concerns around the effect that intellectual property rights were having on global equitable access to health technologies for COVID-19, and the foreseeable inequity of vaccine access which was thought likely to arise once vaccines were approved for use, prompted India and South Africa, in October 2020, to put forward the TRIPS waiver. India and South Africa proposed that World Trade Organization (WTO) members should

'work together to ensure that intellectual property [IP] rights such as patents, industrial designs, copyright and protection of undisclosed information do not create barriers to the timely access to affordable medical products including vaccines and medicines or to scaling-up of research, development, manufacturing and supply of medical products essential to combat Covid-19'.97

Justifying the proposal by reference to 'exceptional circumstances', India and South Africa called for a waiver that would 'continue until widespread vaccination is in place globally, and the majority of the world's population has developed immunity'.

This call has not been heeded at successive WTO meetings, though it received a recent boost in May 2021 via US support for a narrower IP waiver applying only to vaccines against COVID-19.98 Although sometimes referred to in shorthand as a 'patent waiver', in both its original and revised forms the India/South Africa proposal is in fact a broad package, ${ }^{99}$ applicable to diagnostics, treatments and vaccines. It is currently cosponsored by 62 WTO countries (including India/South Africa). ${ }^{100}$ The waiver would apply 'in relation to prevention, containment or treatment of COVID-19', covering not only the temporary waiver of patents (and, where relevant, copyrights) internationally, but also, crucially, the sharing of IP under the umbrella of 'undisclosed information' such as trade secrets and know-how. ${ }^{101}$

96 World Health Organization (WHO), 'Establishment of a COVID-19 mRNA vaccine technology transfer hub to scale up global manufacturing (Expression of interest)' (16 April 2021) https://www.who.int/newsroom/articles-detail/establishment-of-a-covid-19-mrna-vaccine-technology-transfer-hub-to-scale-up-globalmanufacturing

${ }_{97}$ Waiver from Certain Provisions of the TRIPS Agreement for the Prevention, Containment and Treatment of Covid-19. Communication from India and South Africa (2 Oct 2020) IP/C/W/669 https://docs.wto.org/dol2fe/Pages/SS/directdoc.aspx?filename=q:/IP/C/W669.pdf\&Open=True (accessed 24th May 2021). See also Agreement on Trade-Related Aspects of Intellectual Property Rights, Annex 1C of the Marrakesh Agreement Establishing the World Trade Organization (1994) (TRIPS). See revised TRIPS waiver text of 21 May 2021 at https://www.keionline.org/wp-content/uploads/W669Rev1.pdf

98 'Statement from Ambassador Katherine Tai on the Covid-19 Trips Waiver' (5 May 2021) https://ustr.gov/aboutus/policy-offices/press-office/press-releases/2021/may/statement-ambassador-katherine-tai-covid-19-tripswaiver

${ }^{99} \mathrm{~J}$ Bosse, H Y Kang, S Thambisetty, 'There is more to the story than vaccine patents' The Conversation (7 May 2021) https://theconversation.com/trips-waiver-theres-more-to-the-story-than-vaccine-patents-160502

100 Joint Statement of Co-Sponsors to the TRIPS Waiver (17 May 2021) https://www.pmindiaun.gov.in/public files/assets/pdf/Cosponsors' Joint Statement 17 May 2021.pdf

101 Ibid. See revised TRIPS waiver text of 21 May 2021 at https://www.keionline.org/wpcontent/uploads/W669Rev1.pdf. Undisclosed information of commercial nature, such as trade secrets, are protected under Art 39 of TRIPS, 'except where necessary to protect the public'. 
In principle, this kind of 'sharing' is not new. ${ }^{102}$ The 2011 WHO Pandemic Influenza Preparedness (PIP) Framework makes explicit reference to technology transfer, albeit in the somewhat limited context of benefit sharing (in return for receiving biological materials), and it offers language that is short of a legal obligation. However, some of it bears repeating here. Section 6.13 .4 states as follows:

'Influenza vaccine manufacturers who receive PIP biological materials may grant, subject to any existing licensing restrictions, on mutually agreed terms, a nonexclusive, royalty-free licence to any influenza vaccine manufacturer from a developing country, to use its intellectual property and other protected substances, products, technology, know-how, information and knowledge used in the process of influenza vaccine development and production, in particular for pre-pandemic and pandemic vaccines for use in agreed developing countries.'

In line with this, we argue that the TRIPS waiver could help stimulate the building of capacity in LMICs. ${ }^{103}$ As noted earlier, since the coming into force of TRIPS in 1995, LMICs' industrial and pharmaceutical capacity has been hindered by the lack of technology transfer from HICs. ${ }^{104}$ Even when technology has been transferred, undisclosed licensing terms covering patents and other IP rights typically restrict how transferred technologies can be used and to what extent the resultant products - in this case vaccines - may be diffused within and across national boundaries. These issues are complex, and as we explain in the following section, it is vital to consider both patents and trade secrets.

\section{KEY ELEMENTS OF THE PROPOSED TRIPS WAIVER - PATENTS AND TRADE SECRETS}

The TRIPS waiver puts into sharp relief the different layers of property rights that often ringfence innovation and operate as assets in the world economy. ${ }^{105}$ Like a matryoshka doll, the inner core of an invention is often wrapped with different layers of IP rights, each possessing a differing rationale, scope and subject matter. We focus here on the two key IP rights for present purposes: patents and trade secrets (interpreted widely to include know-how, data and other undisclosed information).

A patent is a monopoly on an invention granted to an inventor/owner by one or more patent offices, with specification documentation made public, and which is protected

102 A Kapczynski, ‘Order without Intellectual Property Law: Open Science in Influenza' 102 Cornell Law Review (2017) 1539.

103 P Erfani, LO Gostin and V Kerry, 'Beyond a symbolic gesture: What's needed to turn the IP waiver into Covid19 vaccines' Stat News (19 May 2021) https://www.statnews.com/2021/05/19/beyond-a-symbolic-gesturewhats-needed-to-turn-the-ip-waiver-into-covid-19-vaccines/

104 KC Shadlen, S Guennif, A Guzmán and N Lalitha (Eds.), Intellectual Property, Pharmaceuticals and Public Health: Access to Drugs in Developing Countries (Edward Elgar, 2011).

105 HY Kang, 'Patents as Assets: Intellectual Property Rights as Market Subjects and Objects' in K Birch and F Muniesa (Eds.), Assetization: Turning Things into Assets in Tecbnoscientific Capitalism (MIT Press, 2020). 
Thambisetty, McMahon, McDonagh, Kang, Dutfield
The TRIPS Intellectual Property

Waiver Proposal

exclusively under TRIPS for 20 years. ${ }^{106} \mathrm{~A}$ trade secret (which under TRIPS relates to undisclosed information and can include know-how) is another key monopoly - but by its nature a trade secret is not public; such secrets are instead protected perpetually (usually under contract or non-disclosure agreements (NDAs)). ${ }^{107}$ Such information is protected as long as it can remain secret, tacit, informal or uncodified. ${ }^{108}$ As we explore below, in order for the TRIPS waiver to be fully effective for COVID-19 vaccines, it needs to comprise not only a patent waiver for COVID-19 vaccines, but also provide mechanisms by which trade secrets in the latest vaccine manufacturing know-how can be shared by transferring technology and disclosing data.

In general terms, it is a twist of the patent-trade secret duopoly that IP legal incentives are structured in such a way that inventions that are easily replicable, or reverse-engineered, tend to be patented; for if such an invention lacks patent protection, then it will be easily read, reverse-engineered and reproduced by competitors. On the other hand, if an invention is genuinely difficult to replicate, it may make more strategic commercial sense to hold that inventive information as a trade secret - and potentially obtain longer protection than the 20 years a patent allows. When companies produce and market such a product, they rely on the fact that no one can easily 'read' or reverse-engineer it.

Yet, as we outline below, inadequate patent disclosures, combined with additional formal trade secrets and tacit know-how, can muddy the waters, making it difficult to judge where a legitimate legal incentive ends, and where restrictive practices around sharing of information begin. Such an overlap of varied intellectual property rights with differential levels of - or no - disclosure is exacerbated in a pandemic situation, when trade secrets obstruct the sharing of know-how and the technology transfer needed for COVID-19 vaccine manufacturing.

Put simply, where there is an immediate and extraordinary health need for vaccines to address the global crisis, the ordinary models of information facilitation within the IP system are not enough. For example, although Moderna declared in 2020 that it would not enforce its patents related to COVID-19 vaccines during the pandemic, this decision by Moderna did not encompass all IP, such as trade secrets/know-how, and it excluded techtransfer. ${ }^{109}$ In fact, Moderna recently admitted that without this relevant know-how and technology transfer, others seeking to manufacture their vaccine would face significant hurdles, for example, in scaling manufacturing. ${ }^{110}$ This calls into question the rationale behind their promise not to enforce their patents during the pandemic (and arguably

106 Art 33 TRIPS, states: 'The term of protection available shall not end before the expiration of a period of twenty years counted from the filing date.'

107 Art 39 TRIPS.

108 Agreement on Trade-Related Aspects of Intellectual Property Rights, Annex 1C of the Marrakesh Agreement Establishing the World Trade Organization (1994) (TRIPS).

${ }_{109}$ Z Brennan, 'Moderna CEO brushes off US support for IP waiver, eyes more than $\$ 19 \mathrm{~b}$ in covid-19 vaccine sales in 2021' EndPoints News (6 May 2021) https://endpts.com/moderna-ceo-brushes-off-us-support-for-ipwaiver-eyes-more-than-19b-in-covid-19-vaccine-sales-in-2021/

110 Moderna sees no impact on COVID-19 vaccine from potential patent waiver' Reuters (6 May 2021) https://www.reuters.com/business/healthcare-pharmaceuticals/moderna-raises-2021-sales-forecast-covid-19vaccine-192-bln-2021-05-06/ 
reveals it to be an empty gesture). ${ }^{111}$ As we explore below, the TRIPS waiver must assess ways of facilitating increased production of vaccines via measures addressing both patents and undisclosed information, such as trade secrets.

\section{PATENTS}

Patent law requires disclosure of information relevant to the invention with the aim of ultimately benefiting the public domain of knowledge; yet the operation of this requirement during the pandemic exposes the deficiencies and limits of the way disclosure is doctrinally, normatively and strategically constructed. There are three specific deficiencies which are relevant in the context of the TRIPS waiver. The first of these is the insufficiency of disclosure that has developed doctrinally and in practice that does not necessarily match the requirement of 'disclosure' as a quid pro quo for the grant of a patent monopoly right. The second is the fact that there is a lag in publications of patent applications, either individually, or within patent families, for extended periods of time. The third is demonstrated by the strategic possibilities created by overlapping patent rights. As explored below, taken together these three deficiencies make it difficult to disentangle the patent thicket.

First, patents require inventors to disclose information about their inventions with the patent applicant obliged to describe the invention and enable others in the field to carry out the invention, yet arguably not in significant scientific or technical detail. ${ }^{112}$ The information disclosed at the time of publication of a patent application is not available to the public for use during the duration of the patent. This is a requirement that is expressed in utilitarian terms as the 'patent bargain', though its centrality to theoretical understandings of patents is contested. The many theories that explain how the patent bargain works or ought to work show a fragmented picture - and as Burk and Lemley state, such theories are not 'wrong in as much as they are incomplete' - some are more plausible than others about how patents work or should work in particular industries. ${ }^{113}$ Broadly speaking, the fact that the patent system sets up a 'patent race' - a winner-takesall system for the first to file an application - means that disclosure often occurs very early in the process of filing. In practice, the disclosure requirement underperforms, and speculative filing of merely 'plausible' or 'credible' information is common. ${ }^{114}$ The scepticism about patent disclosures is noted by several scholars who have suspicions about its practical value. ${ }^{115}$

111 Ibid. Moderna has not obtained a licence for the US NIH patent relevant to its vaccine. See C Morten, L Boman, J Rabinovitsj and C Rohr, 'U.S. 10,960,070: The U.S. Government's New Important Coronavirus Vaccine Patent' NYU TLP Clinic Report on NIH's 070 Patent' (14 April 2021), available at https:/ www.dropbox.com/s/1om1v1 kagg7j9dn/NYU\%20TLP $\% 20$ Clinic $\% 20$ Report $\% 20$ on $\% 20 \mathrm{NIH} \% 27 \mathrm{~s} \%$ 20070\%20Patent $\% 2020210414 \% 20 \% 28$ FINAL $\% 29$.pdf?dl $=0$

112 HS Frost, 'The Unique Problem of Inventions Which Are Fully Enabled and Fully Described, But Not Fully Understood (Merrell Dow's Terfenadine Revisited)' 20 Intellectual Property Journal (2007) 369.

113 DL Burk and M Lemley, 'Policy Levers in Patent Law' 89 Virginia Law Review (2003) 1575.

114 JC Fromer, 'Patent Disclosure' 94 Iowa Law Review (2009) 539.

115 See for instance SB Seymore, 'The Teaching Function of Patents' 85 Notre Dame Law Review (2010) 621 and DL Burk, ‘The Role of Patent Law in Knowledge Codification' 23 Berkeley Technology Law Journal (2008) 1009. 
Thambisetty, McMahon, McDonagh, Kang, Dutfield
The TRIPS Intellectual Property

Waiver Proposal

Patent law typically does not mandate further disclosures post-grant, when underlying technologies may become better understood. ${ }^{116}$ This can be a problem for not just for product but also process patents when details regarding manufacturing processes are never revealed in a patent application, or can be fragmented in multiple patent applications. Additionally, information generated to fulfil regulatory requirements (discussed below) is not currently part of, or linked to, the disclosure in related patents. In a substantial body of work, ${ }^{117}$ Arti Rai argues that enhancing patent disclosures through the use of regulatory levers would help patent offices assess whether adequate disclosure has been made in patent applications, which would be valuable not only for competition but also for innovation. 118

Second, intellectual property offices are only obliged to publish patent applications within 18 months of filing and during this period the information is inaccessible to the public. ${ }^{119}$ Therefore, it is not entirely clear at present which patents actually exist in the field of COVID-19 vaccines - a field that has developed rapidly in the last year. In practice, the time at which disclosure truly occurs can be much later, for various reasons. For example, Yale's patent application with GlaxoSmithKline for an mRNA-based malaria vaccine was only published in February 2021 and has a priority date of February 2014, due to the continuation of different patent applications and the practice of grouping them into a single patent family. 120

Third, the existence of overlapping rights also makes it much harder to decipher the IP landscape over some technologies and products. This is related to the first point above and impacts on the exactitude of property boundaries that are necessary for legal transactions. ${ }^{121}$ Multiple patent applications with minor modifications from an original application grow into patent families, with dozens and even hundreds of patents existing over the same product. These overlapping rights can result in a de facto extension of patent protection beyond the initial 20 years. ${ }^{122}$ This is a particularly acute problem in the pharmaceutical industry, where persistently long monopolies created by thickets of patents can arise, making it difficult for competitors to identify whether or not the technology is still protected. ${ }^{123}$ Companies can amass vast numbers of patents in order to hold back and increase the duration and scope of their monopolies - practices that have come under the

116 JC Fromer, 'Dynamic Patent Disclosure' 69 V anderbilt Law Review (2016) 1715.

117 See Rai's body of work including the presentation A Rai, 'Biosimilars and Manufacturing Trade Secrets' (https://www.law.berkeley.edu/files/Rai Arti.pdf) and the in-depth co-authored works: WN Price and A Rai, 'Are Trade Secrets Delaying Biosimilars?' 348 Science (2015) 188; and WN Price and A Rai, 'How Logically Impossible Patents Block Biosimilars' 37 Nature Biotechnology (2019) 862.

118 WN Price II and A Rai, 'Manufacturing Barriers to Biologics Competition and Innovation' 101 Iowa Law Review (2016) 1023 at 1031

119 SB Seymore, 'The Teaching Function of Patents' 85 Notre Dame Law Review (2010) 621.

120 USP Application 2021003085.

121 S Thambisetty, 'Patents as Credence Goods' 27 Oxford Journal of Legal Studies (2007) 707 and MA Lemley and C Shapiro, 'Probabilistic Patents' 19 Journal of Economic Perspectives 75.

122 See details provided by iMak in their presentation, 'The Patent System is a Bottle Neck for Medicines' (17 Dec 2020) https://www.i-mak.org/wp-content/uploads/2020/12/Patents-101-2020-12-17.pdf

$123 \mathrm{O}$ Gurgula, 'Strategic accumulation of patents in the pharmaceutical industry and patent thickets in complex technologies - two different concepts sharing similar features' 48 International Review of Intellectual Property and Competition Law (2017) 385. 
spotlight both in the US ${ }^{124}$ and in the EU. ${ }^{125}$ Even in a relatively novel technological arena, such as in the case of mRNA technologies that are the basis of some of the recently produced COVID-19 vaccines, previous patents exist; indeed, a recent study shows there are already patent thickets in the mRNA field. ${ }^{26}$ Consequently, novel mRNA vaccines already present a fragmented and complex landscape of rights - as confirmed in a recent network analysis study of mRNA vaccine-related patents. ${ }^{127}$ Patent law's disclosure function is therefore quite limited in practice in this context - and any inventive knowledge-dissemination is deferred in its timeframe. In a pandemic, this practical problem hinders the swift sharing of scientific and technical information with the public and within the scientific community.

To summarise, there are at least three (related) problems in the current vaccine-patent landscape: insufficient disclosure, a lack of transparency and the strategic layering of rights that increases the opacity of which technologies are being used or are necessary. On disclosure, we note that despite the narrative of the so-called patent bargain, in reality the patent disclosure model is often inadequate; furthermore, since multiple inventions are required to produce a successful vaccine, what is disclosed in separate patent applications will likely not be sufficient to enable production of a technology like a vaccine which may involve multiple patented inventions. On transparency, it may not be entirely clear what specific patents exist within a field and to whom they belong, which creates thickets. This in turn poses difficulties for other parties wishing to work within the field, potentially limiting (or at least clouding) their freedom to operate, and creating uncertainty about whether their subsequent inventions may be infringing or patentable on their own terms. This uncertainty (as we detail further below) may create situations in which it is unclear whom to ask for a licence to produce a health technology, such as a vaccine, given that many different rights (and rights-holders) may be relevant to the production of any one vaccine. On overlapping patent rights, we observe that this can encourage strategic and opportunistic behaviour on the part of those who claim partial ownership of a technology landscape. We note that such opportunistic behaviour is not a unique function of the pandemic; it is long standing in its nature and it is not prohibited by patent law. Nevertheless, we recognise that it leads to significant constraints on the ability to intervene on public policy grounds both domestically and internationally. Considered together the above three deficiencies of the patent system make it difficult to disentangle the patent thicket, indicating that a specific, limited waiver of (only) patent rights would not be

124 R Knox and G Curfman, 'The Humira Patent Thicket and the Noerr-Pennington Doctrine' (2021) https://ssrn.com/abstract=3781826; See also the ongoing US Congressional investigation into drug-pricing (May 2021)

https://oversight.house.gov/sites/democrats.oversight.house.gov/files/Committee $\% 20 \mathrm{on} \% 20$ Oversight $\% 20 \mathrm{a}$ nd $\% 20$ Reform $\% 20-\% 20$ AbbVie $\% 20$ Staff $\% 20$ Report.pdf

${ }^{125}$ EU Commission, Antitrust: shortcomings in pharmaceutical sector require further action (8 July 2009) IP/09/1098 https://ec.europa.eu/commission/presscorner/detail/en/IP_09_1098

${ }^{126}$ The Penn mRNA patents are licensed to BioNTech; Moderna is using a NIH mRNA patent without a licence, and there are also other university patents on vaccines that use mRNA technology (e.g., Yale). See C Martin and D Lowery, 'mRNA vaccines: Intellectual Property Landscape' 19 Nature Reviews Drug Discovery (2020) 578. https://www.nature.com/articles/d41573-020-00119-8

${ }_{127}$ M Gaviria and B Kilic, 'A network analysis of COVID-19 mRNA vaccine patents' 39 Nature Biotechnology (2021) 546. 
Thambisetty, McMahon, McDonagh, Kang, Dutfield
The TRIPS Intellectual Property

Waiver Proposal

sufficient to make available all the knowledge and information that is in fact needed; as we outline below, a broad IP waiver is required.

\section{Undisclosed Information: Trade SECRETS, NON-Disclosure AgreEments,} DATA EXCLUSIVITY AND REGULATORY EXCLUSIVITY

We define undisclosed information broadly here to include not only trade secrets, but also information about the invention, data gathered during the regulatory approval process, or other kinds of exclusive information - for example, information about dead ends, trials and errors - which are not disclosed to the public. ${ }^{128}$

In contrast to the public interest justification carried by patent law's limited disclosure requirement in return for monopoly rights, trade secrets are, by their nature, not disclosed publicly at all. In normal business practice, holders of IP related to vaccines cannot be obliged to divulge the trade secrets and know-how that are essential for the vaccine manufacturing and distribution process. ${ }^{129}$ This is one of the most evident and difficult to surpass barriers. Relatedly, it has been reported that non-disclosure agreements (NDAs) are in place - for instance, between Pfizer and BioNTech and their suppliers ${ }^{130}$ - which reportedly may legally prevent these companies from participating in initiatives such as CTAP or the WHO's mRNA technology transfer hub. ${ }^{131}$ The extensive use of NDAs has been reported in Malaysia where it was emphasised that a breach could lead to non-delivery of vaccines. ${ }^{132}$

Undisclosed information may also include information that can be protected separately from the IP framework within TRIPS, for example, via 'data exclusivity' rights that ensure that safety data from clinical trials are proprietary. In the US, complex biologics can have 12 years of exclusivity for the originators; and in the EU protection can apply for up to 10 years (up to 8 years' data exclusivity and 2 additional years' marketing exclusivity). ${ }^{133}$

\footnotetext{
128 M Risch, 'Why Do We Have Trade Secrets?' 11 Intellectual Property Law Review (2007) 1 http://scholarship.law.marquette.edu/iplr/vol11/iss1/1

${ }_{129}$ B Mercurio, WTO Waiver from Intellectual Property Protection for COVID-19 Vaccines and Treatments: A Critical Review' Virginia Journal of International Law (forthcoming 2021) https://papers.ssrn.com/sol3/papers.cfm?abstract id=3789820 (accessed 24th May 2021).

130 'Any information that constitutes a trade secret (as defined under Law), in which case Receiving Party will continue to be bound by its obligation of confidentiality and non-use under this Agreement for so long as such information continues to constitute a trade secret, but in no event for a period of less than the five (5) year period specified immediately above.' Supply Agreement Pfizer and BioNTech with TriLink Biotechnologies (9 October 2020) https://contracts.justia.com/companies/maravai-lifesciences-holdings-inc-11469/contract/137780/

131 M Safi, 'WHO platform for pharmaceutical firms unused since pandemic began' The Guardian (22 Jan 2021) https://www.theguardian.com/world/2021/jan/22/who-platform-for-pharmaceutical-firms-unused-sincepandemic-began

132 See details at https://www.nst.com.my/news/nation/2020/12/652459/vaccine-deal-stake-if-info-revealed

133 Medicines Law and Policy, Data Exclusivity in the EU: A Briefing Document (June 2019) available at https://medicineslawandpolicy.org/wp-content/uploads/2019/06/European-Union-Review-of-PharmaIncentives-Data-Exclusivity.pdf - in addition, one more year of protection can be obtained in the EU context for new indications with significant clinical benefit, as noted at 5 .
} 
There is the related concern that in the case of vaccines, issues of regulatory exclusivity (and related secrecy issues) are particularly important. As the technology is new, there is no regulatory pathway for generic versions of, for example, a viral vector vaccine such as the Oxford-AZ one (a complex biologic). In other words, there is no easy answer as to how a new manufacturer 'would scientifically demonstrate that its vaccine is similar enough to one of the existing vaccines to rely on its clinical trial data'. ${ }^{134}$ Even if technical know-how were shared and patents waived, a new generic manufacturer would struggle to bring a product swiftly to the market if the biologics' regulatory data were not shared, because clinical trials would need to be conducted from scratch. Expedited or truncated regulatory pathways are of course possible. For example, the Indian government has granted emergency use approval in India for vaccines which have been granted emergency approval for restricted use by US, European, UK and Japanese regulatory bodies or which are listed in WHO's Emergency Use Listing. ${ }^{135}$

Given these challenges, some commentators claim that the centrality of undisclosed information undermines the case for the TRIPS waiver. ${ }^{136}$ However, as we argue below, these complexities actually underline the need for the eventual text of the waiver to address all IP issues, as part of a broad package of measures enabling increased vaccine production. ${ }^{137}$

\section{HOW THE TRIPS WAIVER CAN ADDRESS BOTH PATENTS AND UNDISCLOSED INFORMATION}

The specific challenges we highlighted above regarding patents (transparency and disclosure) and undisclosed information (trade secrets and know-how, NDAs, data exclusivity, regulatory exclusivity) demonstrate the systemic complexity of the current pharmaceutical model for vaccines. Nevertheless, this should not be read as supporting the case against the proposed TRIPS waiver. Rather, on the contrary, these issues strengthen the case for a comprehensive IP waiver, because in the absence of sufficient voluntary sharing/licensing by industry to meet pandemic needs, a simple patent waiver on its own would not be enough to boost production.

\footnotetext{
${ }^{134}$ JS Sherkow, LL Oullette, N Price and R Sachs, 'Are Patents the Cause of - or Solution to - Covid-19 Vaccine Innovation Problems (No!)?’ (4 Mar 2021) https://writtendescription.blogspot.com/2021/03/are-patentscause-ofor-solution-tocovid.html. In the US, the Consolidated Appropriations Act, 2021 contains provisions affecting the transparency of patent information relating to US Food and Drug Administration (FDA)-licensed biologics.

135 Indian Ministry of Health and Family Welfare Press Release, 13 April 2021 GOI.

136 A Houldsworth, 'TRIPS Covid Vaccine IP Waiver fails to address crucial questions' LAM (20 April 2021) https://www.iam-media.com/coronavirus/trips-covid-vaccine-ip-waiver-proposal-fails-address-crucialquestions

${ }^{137}$ It also bolsters the argument that the waiver may not be an end point, but rather that it can accompany additional measures, where needed. These may include relevant international or national/domestic/regional (e.g., EU) legal measures to be adopted to 'clear the way' of obstacles to efficient operation of the waiver, such as specific measures to address the topics of regulatory data, and to incentivise/mandate sharing of know-how and technology transfer.
} 
Thambisetty, McMahon, McDonagh, Kang, Dutfield
The TRIPS Intellectual Property

Waiver Proposal

The TRIPS waiver as envisaged by India/South Africa would come into play as a temporary waiver of all relevant IP. ${ }^{138}$ This would include, but would not be limited to, patents. Given the problems of disclosure, transparency and overlapping patents outlined above, the benefit of a universal waiver of patents on COVID-19 vaccines and health technologies is that it would allow manufacturers freedom to operate without the risk of litigation or the fear that exported vaccines could be seized in transit and impounded for alleged patent infringement. ${ }^{139}$ As we discuss further (in the next sub-section), the TRIPS waiver has substantial benefits in this respect over the often-cumbersome and onerous system of compulsory licensing of patents.

Trade secrets are vital, and while supporting the waiver, we do not shy away from the challenges highlighted by waiver sceptics. For instance, Hilty et al. argue that it is 'highly unlikely that the waiver of trade secret protection could be effectively implemented and enforced to propel companies to disclose all relevant know-how'. ${ }^{140}$ However, given the absence of adequate industry co-operation on voluntary sharing of trade secrets, this overly pessimistic view ends up propping up a status quo that is failing LMICs. We acknowledge that the circumstances under which entities may be forced to disclose commercially sensitive or tacit technical knowledge may be limited; but they are certainly not without precedent. ${ }^{141}$ In fact, governments can utilise the waiver, and, if necessary, bring into domestic law accompanying measures, to incentivise and mandate the sharing of previously undisclosed information, broadly conceived. ${ }^{142}$ Therefore, we argue in favour of using the TRIPS waiver as part of a 'carrot and stick' approach. Here, the question of whether and when to use incentives ('carrots') for voluntary disclosures, or mandates ('sticks') for the disclosure of previously undisclosed information, is pertinent. In practice, incentives may be more palatable, politically, than mandates. ${ }^{143}$

A combination of incentives and mandates to achieve technology transfer is precisely what happened in the 1940s when, in a wartime situation and with no time to lose, the United States Office of Scientific Research and Development oversaw the pooling of

138 See revised TRIPS waiver text of 21 May 2021 at https://www.keionline.org/wpcontent/uploads/W669Rev1.pdf

139 'Brazil, India denounce Dutch generic drug seizure' Reuters (30 Jan 2009) https://www.reuters.com/article/usdavos-generic/brazil-india-denounce-dutch-generic-drug-seizure-idUSTRE50T27O20090130

140 RM Hilty, PHD Batista, S Carls, D Kim, M Lamping and PR Slowinski, 'Covid-19 and the Role of Intellectual Property: Position Statement of the Max Planck Institute for Innovation and Competition of 7 May 2021' (7 May 2021)

https://www.ip.mpg.de/fileadmin/ipmpg/content/stellungnahmen/20210507 Position statement_Covid_I P waiver.pdf

141 'Throughout 1943, penicillin production became the War Department's No. 2 priority after the Manhattan Project's drive to build a nuclear bomb' as stated in 'How a miracle drug changed the fight against infection during World War II' The Washington Post (11 July 2020) https://www.washingtonpost.com/gdprconsent/?next url $=\mathrm{https} \% 3 \mathrm{a} \% 2 \mathrm{f} \% 2 \mathrm{fwww}$.washingtonpost.com $\% 2$ fhistory $\% 2 \mathrm{f} 2020 \% 2 \mathrm{f} 07 \% 2 \mathrm{f} 11 \% 2 \mathrm{fpenicillin}$ coronavirus-florey-wwii-infection $\% 2 \mathrm{f}$; See also R Bud, Penicillin: Triumph and Tragedy (Oxford University Press, 2007).

142 J Love, 'Buying out know-how to scale vaccine manufacturing' Medium (20 March 2021) https://jamielove.medium.com/buying-know-how-to-scale-vaccine-manufacturing-586bdb304a36

143 Ibid. 
technology which resulted in a massive and rapid scale-up of penicillin production. ${ }^{144}$ Indeed, only last year the US used the Defense Production Act (DPA), invoking national security concerns, in order to scale up domestic vaccine production in Operation Warpspeed. 145

In relation to incentives (or 'carrots'), Jamie Love offers a way to 'unlock' know-how relevant to manufacturing - it could be 'bought out' by governments in certain circumstances. ${ }^{146}$ In terms of mandates (or 'sticks'), the Brazilian Senate has passed a compulsory COVID-19 patent and know-how licensing Bill which may force pharmaceutical companies to share their trade secrets and data (if it proceeds to be approved by the Lower House). ${ }^{147}$ Further to this, German Member of the European Parliament Bernd Lange has proposed that the EU Commission include a clause on technology transfer in future contracts ... so that companies actively transfer knowledge, also to developing countries'. ${ }^{148}$ We note also that Art 73 of TRIPS provides grounds for the suspension of normal TRIPS powers and obligations in times of national emergency.

At a practical level, we also observe that codification of such knowledge is possible in many cases. While corporate trade secrecy often entails tacit knowledge that is, in normal practice, not codified, and thus is difficult to transfer, regulatory requirements sometimes force originator/manufacturers to codify and submit some of this relevant tacit knowledge. ${ }^{149}$

In terms of clinical data in the context of countries where data and marketing exclusivities apply, there have already been calls for a waiver of these exclusivities in order to meet public health needs, including, for example, in the context where a compulsory licence is issued.150 We concur and favour the introduction of a waiver on such data exclusivities (to support the wider TRIPS waiver) in regions/countries where this is relevant.

As noted above, corresponding domestic legislation, such as the US Defense Production Act, can provide a legal basis for sharing trade secrets; ${ }^{151}$ relatedly, domestic legislation could also be employed in order to facilitate the sharing of regulatory data

\footnotetext{
${ }^{144}$ It is unclear how much choice the industry had in the context of penicillin, but it readily agreed; the carrot was likely the legal immunities the industry could expect to benefit from, namely freedom from anti-trust challenges: 'With government permission and exemption from anti-trust legislation, they [the 20 companies involved in manufacture] shared technology with each other and with academic institutions.' R Bud, Penicillin: Triumph and Tragedy (Oxford University Press, 2007), 45.

${ }_{145}$ See details at https://www.defense.gov/Explore/Spotlight/Coronavirus/Operation-Warp-Speed/

$146 \mathrm{~J}$ Love, 'Buying out know-how to scale vaccine manufacturing' Medium (20 March 2021) https://jamielove.medium.com/buying-know-how-to-scale-vaccine-manufacturing-586bdb304a36

147 See details at https://www.iam-media.com/coronavirus/brazilian-senate-passes-compulsory-covid-19-knowhow-licensing-bill and https://www.msn.com/en-in/news/world/brazil-senate-votes-to-suspend-patentprotection-on-covid-19-vaccines/ar-BB1gcwye

148 See Official Letter sent to the EU Commission by Lange and posted by him to social media https://twitter.com/berndlange/status/1394902774832373760

${ }_{149}$ S Parthasarathy, 'Ensuring global access to COVID-19 vaccines' Gerald Ford School of Government Policy Memo (21 Jan 2021)

https://fordschool.umich.edu/news/2021/policy-memo-parthasarathy-ensuring-global-access-covid-19-vaccines

${ }^{150}$ EFM 't Hoen, P Boulet, B Baker, 'Data exclusivity exceptions and compulsory licensing to promote generic medicines in the EU' 10 Journal of Pharmaceutical Policy and Practice (2017) 19. https://www.ncbi.nlm.nih.gov/pmc/articles/PMC5490222/

151 See details at https://www.fema.gov/disasters/defense-production-act
} 
Thambisetty, McMahon, McDonagh, Kang, Dutfield
The TRIPS Intellectual Property

Waiver Proposal

between the relevant medical authorities in one country and those of another. ${ }^{152}$ Sharing of such regulatory submissions (relevant to data exclusivity), which include codified tacit knowledge, would enable others to both increase production and solve follow-on problems regarding, for example, efficiency, speed, fixing bugs, meeting localised conditions and innovating to address variants. Such measures would not be entirely novel and would certainly not be inappropriate in an extraordinary pandemic situation. Greater sharing would enable would-be manufacturers to connect public IP knowledge (e.g., patents), including information which the larger scientific community needs in order to better understand the manufacture of biologics, with regulatory knowledge (data and codified know-how).

In sum, given the extent of the public health crisis we face and the thicket of the patent - trade secret/undisclosed information interface, we must re-evaluate current IP framework and its effects, which are simply not adequate for addressing civilisational challenges such as COVID-19. Crucially, the legal negotiations over the TRIPS waiver offer a way to try to resolve these issues in the political-economic sphere (and may encourage greater industry support for voluntary sharing mechanisms). ${ }^{153}$ We must ask to what extent disclosure and sharing of information can be achieved, and how the waiver can contribute to a solution by either acting as a lever to encourage industry co-operation in non-exclusive, voluntary deals, and/or by putting down a comprehensive legal foundation within the global trading framework to also mandate knowledge sharing and participation in global measures, such as the WHO-led C-TAP initiative. Even before its negotiation and adoption, the TRIPS waiver proposal is already having a positive impact in this regard; for example, it has led to increased transparency about vaccine manufacturing. ${ }^{154}$ In light of growing and widespread pressure in the wake of the waiver proposal, it is logical that companies would prefer a controlled, voluntary transfer of information; the alternative could be to see all IP rights waived, even temporarily, which would occur if the broad language of the original/revised waiver proposal put forward by India and South Africa (which includes section 7, part II of TRIPS - undisclosed information) were retained in any eventual accepted text. ${ }^{155}$

The recommendation of the WHO's Independent Panel for Pandemic Preparedness and Response appears to envisage precisely this: utilising the waiver as leverage by legal

$152 \mathrm{R} \mathrm{Li}$, J Wood, A Baskaran, S Neumann, El Graham, M Levenstein and I Sim, 'Timely access to trial data in the context of a pandemic: the time is now' 10 BMJ Open (2020) https://bmjopen.bmj.com/content/10/10/e039326

${ }^{153}$ Even a waiver sceptic such Bostyn states that the TRIPS waiver proposal will likely have the beneficial effect of pushing pharmaceutical companies to conclude more voluntary agreements. He notes in his conclusion at page 17 that the discourse of the IP waiver in the political sphere will 'make them more willing to license out the manufacturing of the COVID-19 vaccines to third parties, which they have hitherto done only to a very limited extent'. Arguably, this well-made point undermines the narrative thrust of his paper, which is that seeking a waiver is not a good strategy - S Bostyn, 'Why a Covid IP Waiver is not a good strategy' (10 May 2021) https://papers.ssrn.com/sol3/papers.cfm?abstract id $=3843327$

${ }_{154}$ P Erfani, LO Gostin and V Kerry, 'Beyond a symbolic gesture: What's needed to turn the IP waiver into Covid19 vaccines' Stat News (19 May 2021) https://www.statnews.com/2021/05/19/beyond-a-symbolic-gesturewhats-needed-to-turn-the-ip-waiver-into-covid-19-vaccines/

155 See revised TRIPS waiver text of 21 May 2021 at https://www.keionline.org/wpcontent/uploads/W669Rev1.pdf 
threat. As noted earlier, the Panel recommends that the WHO and WTO work together to seek voluntary agreement to facilitate technology transfer and voluntary licensing for COVID-19 vaccines; and in the absence of this agreement within 3 months, a TRIPS waiver should come into effect immediately. ${ }^{156}$ Currently, there is no legal incentive or mandate for key players to see this crisis as an opportunity to articulate a more equitable and ethical mode of practice of global solidarity. That is why the TRIPS waiver, rather than the (current) burdensome compulsory licensing system, is needed. The alternative is the status quo - nationalistic and opportunistic behaviour and the quest for 'super profits' amid inequalities of production and distribution. ${ }^{157}$

\section{DO COMPULSORY LICENCES PROVIDE AN ALTERNATIVE TO THE TRIPS WAIVER?}

A common argument which has been raised in opposition to the waiver proposal has been to suggest that since the W'TO system already allows for compulsory licensing, there is no need for a waiver. ${ }^{158}$ It is true that compulsory licensing offers a potential alternative to allow third parties to use technologies covered by intellectual property rights in the absence of rights-holders' permission. In cases of 'a national emergency or other circumstances of extreme urgency or in cases of public non-commercial use' the TRIPS Agreement allows for the forgoing of the general requirement that there should first be an attempt to negotiate a voluntary licence with the IP rights holder before a compulsory licence (CL) is issued. The COVID-19 context would likely be viewed as one such emergency. ${ }^{159}$ Yet, as shown above, the fragmented and complex existing IP landscape - as highlighted in a recent network analysis study of mRNA vaccine-related patents ${ }^{160}$ - is a key reason why the existing system of compulsory licensing under TRIPS, and more generally the current 'TRIPS flexibilities'161 for public health, are not well suited to addressing vaccine needs during the COVID-19 pandemic.

\footnotetext{
156 The Independent Panel, 'COVID-19: Make it the Last Pandemic' (May 2021) at 14 https://theindependentpanel.org/wp-content/uploads/2021/05/COVID-19-Make-it-the-LastPandemic final.pdf

157 A term used by SII CEO Adar Poonawalla as quoted in 'How Profitable is Adara Poonawalla's Serum Institute?' Business Today (14 May 2021) https://www.businesstoday.in/current/corporate/how-profitable-is-adarpoonawalla-serum-institute/story/439018.html

158 EFM 't Hoen, 'Covid-19 and the comeback of compulsory licensing' Medicines Law and Policy (23 Mar 2020)

https://medicineslawandpolicy.org/2020/03/covid-19-and-the-come-back-of-compulsory-licensing/ (accessed 24th May 2021).

159 A McMahon, 'Global equitable access to vaccines, medicines and diagnostics for COVID-19: The role of patents as private governance' 47 Journal of Medical Ethics (2021) 142.

${ }^{160}$ M Gaviria and B Kilic, 'A network analysis of COVID-19 mRNA vaccine patents' 39 Nature Biotechnology (2021) 546

161 'TRIPS flexibilities' is a frequently used phrase in the context of countries' room for manoeuvre in terms of their domestic interpretation of TRIPS in pursuit of certain public policy goals such as enhancing access to medicines. They include, but are not necessarily limited to: (i) vague language of many of the TRIPS provisions, (ii) the declared objectives and principles (Articles 7 and 8) which contain positive language for LMICs, (iii) omissions (e.g., on new use patents) and immunities (e.g., the non-justiciability of exhaustion of rights regimes), (iv) the availability of public policy safeguards (such as compulsory licensing), exclusions and exceptions to rights - like
} 
Thambisetty, McMahon, McDonagh, Kang, Dutfield
The TRIPS Intellectual Property

Waiver Proposal

In a pandemic context, seeking to use compulsory licensing under the standard criteria provided for a CL in TRIPS, as a solution to achieving global equitable access to vaccines on the scale and timeline needed for COVID-19 has six significant drawbacks given the general requirements for a CL under TRIPS. ${ }^{162}$ The first is that a CL can only be applied on a product-by-product, and country-by-country basis. A blanket CL in all states for, for example, COVID-19 vaccines is not possible under TRIPS. Second, the WTO system sets down minimum criteria for a CL to be used in WTO states under Art 31 of the TRIPS Agreement, but national states can impose additional requirements for a CL, meaning the procedures for obtaining a CL at the national level can often be bureaucratic, uncertain and/or time consuming. Third, despite a CL being a flexibility allowed for by TRIPS, some states have traditionally been (understandably) reluctant to invoke the process for issuing a CL, including due to fears of challenge and/or of trade sanctions being imposed on them (which has happened in the past). ${ }^{163}$

The fourth issue is that, as noted above, there are additional obstacles to the use of a CL for vaccines, including regulatory obstacles. ${ }^{164}$ For instance, as stated earlier, in some regions including the $\mathrm{EU}$, there are additional protections for clinical trial data such as data and marketing exclusivities which mean that generic producers cannot use such data when seeking regulatory approval for a generic product during a certain period of time. ${ }^{165}$ This means that obtaining generic approval may not be possible in a timely manner for such products - this has proven to be a stumbling block against use of a CL in Europe. ${ }^{166}$ Such requirements may also impede the use of CLs for COVID-19 in some contexts. Fifth, when a CL is issued, the rights holder must be provided with adequate renumeration, and challenges can arise around what is 'adequate' in a pandemic context. ${ }^{167}$ Notably, in this and other contexts, negotiating with pharmaceutical companies can be challenging and subject to asymmetry of information and predatory delays. Sixth, Art 31(f) of TRIPS states that products made under a CL must be used 'predominantly for supply of the domestic market'; however, because of changes introduced by Art 31 bis, ${ }_{168}$ in theory a CL for export and import is now possible for WTO states. Yet there are obstacles to the use of Art 31 bis, including the fact that some countries/regions (such as the EU) have opted out of Art

the Bolar (regulatory review) exemption, rendered permissible in conformity with an adopted WTO panel report, and (v) Article 73 security exceptions whose scope is somewhat unclear but may in fact be extremely broad.

162 This reflects on arguments raised previously in A McMahon, 'Global equitable access to vaccines, medicines and diagnostics for COVID-19: The role of patents as private governance' 47 Journal of Medical Ethics (2021) 142.

163 EFM 't Hoen, J Veraldi, B Toebes, et al., 'Medicine procurement and the use of flexibilities in the agreement on Trade-Related aspects of intellectual property rights, 2001-2016' 96 Bull World Health Organ (2018) 85. A nonexhaustive list of flexibilities under TRIPS (including use of compulsory licensing) and their use within the health context is available here: http://tripsflexibilities.medicineslaw andpolicy.org/ (Accessed 24th May 2021).

${ }^{164}$ EFM 't Hoen, P Boulet, BK Baker, 'Data exclusivity exceptions and compulsory licensing to promote generic medicines in the European Union: A proposal for greater coherence in European pharmaceutical legislation' Journal of Pharmaceutical Policy and Practice (2017) 10

165 Ibid.

${ }^{166}$ EFM 't Hoen, J Veraldi, B Toebes, et al., 'Medicine procurement and the use of flexibilities in the agreement on Trade-Related aspects of intellectual property rights, 2001-2016' 96 Bull World Health Organ (2018) 85.

${ }^{167} \mathrm{H}$ Wong, 'The case for compulsory licensing during COVID-19' 10 Journal of Global Health (2020)

168 Amendment of the TRIPS Agreement. WTO Doc. WT/L/641 (Dec. 8,2005) (hereafter Article 31 bis) 
31 bis as importing members. ${ }^{169}$ On this, there have been calls, which we support, for $\mathrm{HICs} /$ regions who have opted out of this system to opt back in, given the risks posed by the COVID-19 context. ${ }^{170}$

Furthermore, the conditions for using Art 31 bis for states with limited manufacturing capacity are highly onerous, and there are limited incentives for third parties to assist in provision of products under a CL for export. Indeed, to date this provision has only ever been used effectively once, when Rwanda obtained access to generic HIV TriAvir by importing this from the Canadian company Apotex. ${ }^{171}$ However, even in that context, Rwanda notified the WTO Council of its intent to use this mechanism in July 2007, but did not obtain its first shipment of medicines until 15 months later, in 2008. ${ }^{172}$ Since the US announced support for the waiver in early May 2021, Bolivia has made a declaration to the WTO that it is seeking supply of vaccines from Canada under Art 31 bis (for compulsory licence), which is a welcome development. Yet Bolivia's application also indicates, once again, the limits of Art 31 bis when applied in a rapidly evolving technological and heavily patented field. ${ }^{173}$

Thus, compulsory licensing under the TRIPS system has considerable drawbacks, including: the lack of detailed knowledge about the web of patents which may be applicable to any vaccine, inadequate information about manufacturing or regulatory processes, the terms of cross-licensing (because licence agreements are not disclosed to the public) and limited knowledge about the contents of the patent applications which may be relevant for a CL application as many are still unpublished by the relevant patent offices. Such issues make the effective use of CLs for vaccines very difficult in both the domestic and Art 31 bis context. Bolivia's W'TO filing demonstrates poignantly that such a lack of transparency around applicable patents makes it difficult to determine which patents and patent applications are relevant for a CL process in the first place. ${ }^{174}$ Thus, for these reasons, in the context of seeking a timely global solution for vaccine equity in the COVID-19 context, we argue that merely relying on compulsory licensing on its own under the

169 For a list of opt-out countries, see WTO, 'Annex and Appendix to the TRIPS Agreement (note 3) https://www.wto.org/english/docs e/legal e/31bis trips annex e.htm; see also A McMahon, 'Global equitable access to vaccines, medicines and diagnostics for COVID-19: The role of patents as private governance' 47 Journal of Medical Etbics (2021) 142.

170 See details at https://medicineslawandpolicy.org/2020/04/never-say-never-why-the-high-income-countriesthat-opted-out-from-the-art-31bis-wto-trips-system-must-urgently-reconsider-their-decision-in-the-face-of-thecovid-19-pandemic/

${ }^{171} \mathrm{H}$ Hestermeyer, 'Canadian-made Drugs for Rwanda: The First Application of the WTO Waiver on Patents and Medicines' ASIL Insights (10 December 2007) https://www.asil.org/insights/volume/11/issue/28/canadianmade-drugs-rwanda-first-application-wto-waiver-patentsand \#: : :text $=$ Article $\% 2031 \% 20$ of $\% 20$ the $\% 20$ TRIPS, within $\% 20 \mathrm{a} \% 20$ reasonable $\% 20$ period $\% 20$ of

172 B Anderson, 'Better Access to Medicines: Why Countries are getting "Tripped" up and Not Ratifying Article 31 Bis' Case Western Reserve Journal of Law, Technology and the Internet (2010) 165.

173 With specific reference to current mRNA vaccines see M Gaviria and B Kilic, 'A network analysis of COVID19 mRNA vaccine patents' 39 Nature Biotechnology (2021) 546.

174 The Bolivian government states that it is not clear if the product for which a CL is sought is protected by patents in its territory: the matter is 'To be determined'. Bolivia's notification of its intent to use the Art. 31 bis CL mechanism states as a response to the category ‘ ¿Está(n) el/los producto(s) necesario(s) protegido(s) mediante patente en el territorio?': 'Por determinarse. En la medida en que se hayan solicitado u otorgado patentes para los productos necesarios, el Estado Plurinacional de Bolivia tiene la intención de concederlicencias obligatorias, de conformidad con los artículos31 y 31bisdel Acuerdo sobre los ADPIC.' https://docs.wto.org/dol2fe/Pages/SS/directdoc.aspx?filename=s:/IP/N/9BOL1.pdf\&Open=True 
Thambisetty, McMahon, McDonagh, Kang, Dutfield
The TRIPS Intellectual Property

Waiver Proposal

existing TRIPS framework, in the absence of industry providing greater support for voluntary licensing measures, has significant limitations.

It is also important to not make the error of viewing the TRIPS waiver and compulsory licensing as entirely an 'either/or' situation. It is possible to argue in favour of reciprocity between the two approaches. We note that COVID-19 has already resulted in some countries modifying compulsory licensing laws to make it easier for CLs to be used at the national level in the pandemic or in broader public health contexts. ${ }^{175}$ This is positive, and it is our view that all states should be encouraged to do similarly as soon as possible. Indeed, unlike in the past, today there may be greater state willingness for CLs to be used to address at least some issues of the COVID-19 pandemic because, as noted above, the TRIPS waiver has shifted the political balance in favour of CL use. On this, CLs may be particularly useful in the context of therapeutics, diagnostics and medical equipment - as these are typically easier to reverse-engineer in practice than vaccines are. Recent US support for a TRIPS waiver was accompanied by the use of permissive language on CLs (in the relevant US Trade Representative report). ${ }^{176}$ This is welcome: it should boost legal and operative measures in developing countries to protect public health and encourage use of CLs in the COVID-19 context. This would be yet another positive political impact of the TRIPS waiver.

We favour the tandem pursuit of CLs (where specific state needs can be addressed) and the TRIPS waiver (to achieve universal benefits). ${ }^{177}$ It does not need to be an either/or approach. CLs may prove useful in some areas of health technology, and, as noted above, utilising CLs may now be less burdensome considering the positive US reaction to the TRIPS waiver proposal and associated USTR language on CLs. This is arguably another achievement flowing from the growing momentum and support behind the TRIPS waiver. Nonetheless, as we outlined in the previous section, a universal TRIPS waiver offers clear benefits that the mere use of CLs under TRIPS simply cannot achieve. The waiver is also a legal and political lever to encourage and mandate technology transfer and the sharing of trade secrets and other data such as industry participation in voluntary schemes like the C-TAP. In sum, the waiver offers a far wider-ranging proposition than what the mere use of CLs under TRIPS parameters can achieve.

175 A McMahon, 'Patents, access to health and COVID-19 - The role of compulsory and government-use licensing in Ireland' 71 NILQ (2020) 331.

176 Office of the US Trade Representative (USTR), 2021 Special 301 Report (2021) at 34 https://ustr.gov/sites/default/files/files/reports/2021/2021\%20Special $\% 20301 \% 20$ Report $\% 20$ (final).pdf

177 Indeed, if the waiver were adopted, this would clear the way for use of CL at a domestic level, as noted in JL Contreras, 'US Support for a WTO Waiver of COVID-19 Intellectual Property - What Does it Mean?' (7 May 2021) https://blog.petrieflom.law.harvard.edu/2021/05/07/wto-waiver-intellectual-property-covid/ 


\section{WHAT WILL THE IMPACT OF THE TRIPS WAIVER BE ON THE GLOBAL IP SYSTEM?}

The current discussion around the TRIPS waiver has exposed disagreements among academics and legal scholars about whether the waiver could jeopardise future ability to respond to other global challenges by weakening the incentives for pharmaceutical innovation. ${ }^{178}$ As we outline below, in order to understand this argument it must be considered from both sides of the patent bargain, in the context of the pandemic, and with reference to the history of the pharmaceutical industry in the pre- and post-TRIPS eras.

\section{ANALysing the ARgument That the tRIPS Waiver Will WeAKen INNOVATION INCENTIVES}

The assumption that patents create positive incentives for innovation is oft stated, but it is actually highly contested within academic scholarship. An overview of general law and economics literature on the patent bargain offers neutral to negative support for such a claim. ${ }^{179}$ The patent bargain, which provides the utilitarian justification of patent rights, namely that a private monopoly right is justified for the public good, requires calculation of values that are difficult to quantify. ${ }^{180}$ Landes and Posner, in their economic analysis of IP law, remark: '[W] hether the benefits exceed the costs is impossible to answer with confidence on the basis of present knowledge.' ${ }^{181}$ In the context of the ongoing US House of Representatives Hearing on Unsustainable Drug Prices, James Love ${ }^{182}$ states that 'there is no connection between the incentives needed to induce investments in biomedical innovation and the ultimate cost of the incentives', effectively delinking patent incentives from biomedical innovation. ${ }^{183}$

Even if one accepts the rhetoric of 'IP as innovation incentives' generally, our position is that it makes very little sense in the extraordinary context of COVID-19-related IP, especially in relation to patent and trade secrets on vaccines. This is because the COVID19 vaccine market has been created to a large degree by public subsidies. Advance market orders by individual governments and COVAX have de-risked vaccine developments to such a degree in this context that it makes very little sense to privatise the fruits of public

178 RM Hilty, PHD Batista, S Carls, D Kim, M Lamping and PR Slowinski, 'Covid-19 and the Role of Intellectual Property: Position Statement of the Max Planck Institute for Innovation and Competition of 7 May 2021' (7 May 2021)

https://www.ip.mpg.de/fileadmin/ipmpg/content/stellungnahmen/2021 0507 Position statement Covid I P waiver.pdf

179 F Lévêque and Y Ménière, 'Patents and Innovation: Friends or Foes?' UC Berkeley Recent Worke (2007) https://escholarship.org/uc/item/2w8605xg; A Jaffe and J Lerner, Innovation and its Discontents (Princeton: Princeton University Press, 2007); J Bessen and M Meurer, Patent Failure: How Judges, Bureaucrats, and Lanyers Put Innovators at Risk (Princeton: Princeton University Press, 2009).

${ }^{180} \mathrm{M}$ Biagioli, 'Weighing intellectual property: Can we balance the social costs and benefits of patenting?' 57 History of Science (2019) 140 - doi:10.1177/0073275318797787.

181 W Landes and R Posner, The Economic Structure of Intellectual Property Law (Harvard University Press, 2003) 310 (at n 5), quoted in M Biagioli (2018) n 154.

182 Director, Knowledge Ecology International (KEI) https://www.keionline.org/jamie

183 J Love, 'KEI statement in House hearing on Unsustainable Drug Prices (Part III)' KEI (19 May 2021) https://www.keionline.org/36222 
Thambisetty, McMahon, McDonagh, Kang, Dutfield
The TRIPS Intellectual Property

Waiver Proposal

funding with the additional 'incentive' of private monopoly rights. In fact, as we note above, there is a tangible risk that privately held IP monopolies and profit maximisation strategies may actually create the wrong incentives in the short-term in a pandemic context, prioritising the production and distribution of HICs' booster doses rather than first doses for LMICs. ${ }^{184}$ Given that vaccine markets cannot be understood as entirely privately ordered markets, we must also acknowledge that in the medium to long term they may respond differently to IP incentives, which operate with a forward-looking timeframe. In the past, the market has not been very good at responding to calls for pandemic preparedness, in part because of the way such incentives are structured. ${ }^{185}$

Therefore, and despite what some commentators argue, in the context of COVID19 vaccines we are not in a 'normal' incentive/reward situation. ${ }^{186}$ The argument that the COVID-limited, temporary TRIPS IP waiver will de-incentivise R\&D in all other areas of science/technology (where IP protections remain unaffected) is thus unconvincing. ${ }^{187}$ Defenders of the status quo in the COVID-19 context tend to under-state the risks of the current pandemic for global public health and over-state the risk to the overall IP system from the temporary COVID-focused IP waiver proposal. In fact, as we note above, there is a danger that the IP system could create the wrong incentives if the market is left to regulate such issues. Patents are not only valued for monopoly pricing power but also as strategic and financial assets. ${ }^{188}$ The forward-looking speculative value of patents for maintaining pricing and market monopoly explains the paradoxical arguments of the waiver opponents: they argue that the waiver will not change a thing, yet they also argue that it will disincentivise their operation in the future. ${ }^{189}$

\section{THE IMPORTANCE OF Understanding How INCENTIVES Have OpERATED IN THE PRE- AND POST-TRIPS ERAS}

An undifferentiated and uncritical understanding of patents as incentives neglects the fact that the patent bargain plays out differently in various nation states, so that it is difficult to apply the same IP justification across varied jurisdictions. The incentive narrative may make sense in a HIC domestic system (e.g., German or UK) or for different inventive

${ }^{184} \mathrm{~N}$ Triggle, 'UK orders another 60m from Pfizer' BBC (28 April 2021) https://www.bbc.co.uk/news/uk$\underline{56921018}$

185 See J\&J CEO statement at 'Researchers are racing to make a coronavirus vaccine: will it help?' New York Times (28 January 2021) https://www.nytimes.com/2020/01/28/health/coronavirus-vaccine.html

186 RM Hilty, PHD Batista, S Carls, D Kim, M Lamping and PR Slowinski, 'Covid-19 and the Role of Intellectual Property: Position Statement of the Max Planck Institute for Innovation and Competition of 7 May 2021' (7 May 2021)https://www.ip.mpg.de/fileadmin/ipmpg/content/stellungnahmen/2021 0507 Position statement C ovid IP waiver.pdf

187 S Thambisetty, 'Why Patent Law Doesn't Do Innovation Policy' LSE Legal Studies Working Paper No. 20/2013 https://ssrn.com/abstract $=2328173$

188 HY Kang, 'Patents as Assets: Intellectual Property Rights as Market Subjects and Objects' in K Birch \& F Muniesa (Eds.), Assetization. Turning Things into Assets in Technoscientific Capitalism (MIT Press, 2020) 75-95.

${ }^{189} \mathrm{G}$ Chazan, E Solomon, H Kuchler and J Brundsen, 'Angela Merkel rejects US move to waive patents on vaccines' Financial Times (6 May 2021) https://www.ft.com/content/76a05a85-b83c-4e36-b04d-7f44f63e57b0 
fields in science and technology. ${ }^{190}$ Yet we must not ignore the fact that transnational IP law fails to account for differential national socio-economic conditions in different states, including highly varied capacities to acquire and absorb technologies from elsewhere, whether through foreign direct investment, licensing or other means. Indeed, TRIPS was not designed to accommodate meaningfully such variation, despite some favourable language in Articles 7191 and 66.192

As a result, the IP-dominant framing of innovation has contributed to both the systematic inability to meet local needs and the underdevelopment of vaccine production in LMICs. ${ }^{193}$ In normal times, vaccine markets in HICs tend to be small, and are akin to other instances of chronic underfunding, such as orphan drugs. ${ }^{194}$ Vaccines for LMICs are usually procured and delivered as public goods at low cost, and are not typically profitable when compared to medicines with recurring treatment costs. 195 There are prominent examples of market failures with respect to producing vaccines for LMICs. ${ }^{196}$ Failures also occurred in the emergency responses to Zika and Ebola. ${ }^{197}$ Precisely because the conventional IP incentives have so far failed to meet the needs of the poor with respect to some of the most lethal diseases in the world, such as malaria, we must resist calls to defend uncritically such incentives now, in a global pandemic. ${ }^{198}$

${ }^{190}$ RM Hilty, PHD Batista, S Carls, D Kim, M Lamping and PR Slowinski, 'Covid-19 and the Role of Intellectual Property: Position Statement of the Max Planck Institute for Innovation and Competition of 7 May 2021' (7 May 2021)

https://www.ip.mpg.de/fileadmin/ipmpg/content/stellungnahmen/2021 0507 Position statement Covid I $\mathrm{P}$ waiver.pdf

191 Art 7 TRIPS states: 'The protection and enforcement of intellectual property rights should contribute to the promotion of technological innovation and to the transfer and dissemination of technology, to the mutual advantage of producers and users of technological knowledge and in a manner conducive to social and economic welfare, and to a balance of rights and obligations.'

192 Art 66, TRIPS states:

'1. In view of the special needs and requirements of least-developed country Members, their economic, financial and administrative constraints, and their need for flexibility to create a viable technological base, such Members shall not be required to apply the provisions of this Agreement, other than Articles 3, 4 and 5 , for a period of 10 years from the date of application as defined under paragraph 1 of Article 65. The Council for TRIPS shall, upon duly motivated request by a least-developed country Member, accord extensions of this period; 2. Developed country Members shall provide incentives to enterprises and institutions in their territories for the purpose of promoting and encouraging technology transfer to leastdeveloped country Members in order to enable them to create a sound and viable technological base.'

193 A Irwin, 'How COVID spurred Africa to Plot a Vaccine Revolution' Nature (21 April 2021) https://www.nature.com/articles/d41586-021-01048-1

194 AS Rutschman, 'The Mosaic of Coronavirus Vaccine Development: Systemic Failures in Vaccine Innovation' 21 Saint Louis University School of Law - Legal Studies Research Paper Series (2020)

195 AS Monto, 'Vaccines and Antiviral Drugs in Pandemic Preparedness' 12 Emerging Infectious Diseases (2006) 55.

196 DC Kaslow, S Black, DE Bloom, M Datla , D Salisbury \& R Rappuoli, 'Vaccine candidates to poorer nations are going to waste' 564 Nature (27 December 2018) 334 https://www.nature.com/articles/d41586-018-07758-3

197 Supra fn 6; With respect to the Ebola vaccine, 'Canadian government scientists drove the development of rVSVZEBOV, from laboratory bench to a commercial grade product for use in clinical trials, while private sector partners failed to substantively advance development in the years leading up to the [2014-15] epidemic' as stated in M Herder, JE Graham and R Gold, 'From discovery to delivery: public sector development of the rVSVZEBOV Ebola vaccine.' 7 Journal of Law and the Biosciences (2020) 1-14; See also 'Ebola outbreak: why has "big pharma" failed deadly virus victims?' The Independent (7 September 2014) https://www.independent.co.uk/lifestyle/health-and-families/health-news/ebola-outbreak-big-pharma-failed-victims-why-9716615.html

198 J Lezaun and CM Montgomery, 'The Pharmaceutical Commons: Sharing and Exclusion in Global Health Drug Development' 40 Science, Technology, \& Human V alues (2015) 3. doi:10.1177/0162243914542349 
Thambisetty, McMahon, McDonagh, Kang, Dutfield
The TRIPS Intellectual Property

Waiver Proposal

Rather we should acknowledge that as innovation incentives, IP rights have, at best, globally uneven results. Economic studies demonstrate that, as internationally structured, they cannot serve differential international public interests equally well because there is insufficient space for countries to tailor their design domestically to fit local needs and conditions. ${ }^{199}$ Indeed, there is much data to support claims that due to TRIPS, developing countries' long-standing position as 'importers' of technology may become permanent, 200 ensuring that their ability to participate in the global knowledge economy remains marginal. This context drives much of the international opposition to the present status quo of what may be deemed 'IP maximalism'.

The rhetoric of IP maximalism around the TRIPS Agreement among net exporter nations and transnational corporations has often taken on moralistic and natural property rights hues. Yet, IP rights are historical monopolies that have become socially constructed rights: they are not 'discovered' or natural property rights. ${ }^{201}$ They are not held in perpetuity and provided by state(s) in return for a quid pro quo to meet certain innovation incentives (though as we note above, these incentives operate unevenly). During the 19th and 20th centuries several major states, including, for example, the Netherlands, abolished patent rights for a period in order to build up domestic industry; while others deliberately weakened IP rights to enhance domestic technological capacities. ${ }^{202}$ Several countries, including those which now feature leading pharmaceutical corporations, were for a long time hesitant to allow medicines to be patentable:

'Pharmaceutical products only became patentable in France in 1960, in Ireland in 1964, in Germany in 1968, in Japan in 1976, in Switzerland in 1977, in Italy and Sweden in 1978, and Spain in 1992. Interestingly, a few developing countries acted in the reverse direction. For example, in the late 1960s and early 1970s Brazil and India passed laws to exclude pharmaceuticals as such from patentability (as well as

${ }^{199}$ Sanjaya Lall's research finds ample evidence that 'the need for IPRs varies with the level of development'. Based in part on the work of Keith Maskus, Lall states:

'Many rich countries used weak IPR protection in their early stages of industrialisation to develop local technological bases, increasing protection as they approached the leaders. Econometric cross-section evidence suggests that there is an inverted-U shaped relationship between the strength of IPRs and income levels. The intensity of IPRs first falls with rising incomes, as countries move to slack IPRs to build local capabilities by copying, then rises as they engage in more innovative effort. The turning point is $\$ 7,750$ per capita in 1985 prices ..., a fairly high level of income for the developing world.'

S Lall with M Albaladejo, 'Indicators of the Relative Importance of IPRs in Developing Countries' Issues Paper no. 3, UNCTAD-ICTSD Project on Intellectual Property Rights and Sustainable Development, Geneva (2003) (though a relatively old study, new evidence to disprove this general thesis is lacking).

200 Commission on Intellectual Property Rights (CIPR), Integrating Intellectual Property Rights and Development Policy: Report of the Commission on Intellectual Property Rights (2002). For an article citing and commenting on the various arguments about this, see G Dutfield, 'The Limits of Substantive Patent Law Harmonization' in RL Okediji and MA Bagley (Eds.), Patent Law in Global Perspective (Oxford University Press, 2014) 127-146.

201 M Biagioli, 'Patent Republic' 73 Social Research (2006) 1129. See also F Machlup and E Penrose, 'The Patent Controversy in the Nineteenth Century' 10 Journal of Economic History (1950) 1.

202 G Dutfield, That High Design of Purest Gold: A Critical History of the Pharmaceutical Industry, 1880-2020 (World Scientific Publishing, 2020). 
processes to manufacture them in Brazil's case). TRIPS compliance, though, has required these countries to change direction again. India finally allowed drugs to be patented, albeit with some continuing restrictions, in 2005.'203

The strong underlying features of the current Indian and Brazil pharmaceutical industries can to some extent be traced to this pre-TRIPS period, when patent rights were weak or severely limited.204 By contrast, post-TRIPS, LMICs have been hindered from developing pharmaceutical capacity due to strong IP rights and a lack of technology transfer. ${ }^{205}$ However, when IP rights are couched in 'property' terms, often naturalised without a regard for their overall social justification, this important history is lost. ${ }^{206}$ Thus, different understandings of IP rights - as historically contingent or as near-absolute property rights - appear to be one of the fault lines in the academic debate on the scope of the waiver. ${ }^{207}$

IP maximalist views are often expressed in the form of nationalistic complaints of other countries 'stealing' 'our' innovations. ${ }^{208}$ In a recent interview the Curevac investor Friedrich von Bohlen remarked that US support for a TRIPS waiver is an attempt to disrupt the German firms Curevac and BioNTech:

'Germany's post-war constitution says that human life is inviolable, I'd say the same about intellectual property ... If the firms were all American, I don't think we'd have had this proposal.'209

Aside from the highly problematic - morally and legally - equation of the right to human life with rights to intellectual property, ${ }^{210}$ this statement also ignores the fact that the current mRNA technology is based on Hungarian, Japanese and American scientists' research in different countries, and is the product of cumulative, cross-national

${ }^{203}$ G Dutfield and U Suthersanen, Dutfield and Suthersanen on Global Intellectual Property Law (Edward Elgar, 2020), 172.

204 Ibid.

205 See generally G Krikorian and A Kapczynski (Eds.), Access to Knowledge in the Age of Intellectual Property (Zone Press, 2010). See also S Ragavan and A Vanni (Eds.), Intellectual Property Law and Access to Medicine: TRIPS Agreement, Health, and Pharmaceuticals (Routledge, 2021).

206 GS Alexander, EM Penalver, J Singer and L Underkuffler, 'A statement of progressive property' 94 Cornell Law Review (2009) 743.

${ }^{207}$ RM Hilty, PHD Batista, S Carls, D Kim, M Lamping and PR Slowinski, 'Covid-19 and the Role of Intellectual Property: Position Statement of the Max Planck Institute for Innovation and Competition of 7 May 2021' (7 May 2021) at

https://www.ip.mpg.de/fileadmin/ipmpg/content/stellungnahmen/2021 0507 Position statement_Covid_I P waiver.pdf

${ }^{208}$ S Oddi 'TRIPS - Natural Rights and a Polite Form of Economic Imperialism' 29 V anderbilt Journal of Transnational Law (1996) 415.

209 D Scally, 'Curevac investor sees bright future for German vaccine maker' The Irish Times (20 May 2021) https://www.irishtimes.com/business/health-pharma/curevac-investor-sees-bright-future-for-german-vaccinemaker-1.4568758

${ }^{210}$ Committee on Economic, Social and Cultural Rights, Statement on universal affordable vaccination for COVID-19, international cooperation and intellectual property E/C.12/2021/1 which states: '[B]usiness entities should also refrain from invoking intellectual property rights in a manner that is inconsistent with the right of every person to access a safe and effective vaccine for COVID-19 or to the right of States to exercise TRIPS flexibilities.' 
Thambisetty, McMahon, McDonagh, Kang, Dutfield
The TRIPS Intellectual Property

Waiver Proposal

investigations. ${ }^{211}$ In addition, the claim that the TRIPS waiver may result in certain states losing a technological and competitive lead, as voiced by the pharmaceutical industry, needs to be understood in this context: it is an admission of the present benefits that some countries and companies enjoy as a result of the TRIPS system. ${ }^{212}$ These are hard to cede. Nonetheless, we are in an extraordinary situation; consequently, extraordinary measures, ${ }^{213}$ such as the TRIPS waiver, ought not to be viewed as disproportionate to global needs. ${ }^{214}$

\section{The Other Side of the 'Patent Bargain’: Do the COVID-19 Patents Serve THE GLOBAL PuBLIC?}

Looking to the other side of the 'patent bargain', we argue that the public good that transnational patent law needs to serve, particularly in a pandemic situation, must be a global public good. ${ }^{215}$ On production and price, this side of the bargain has not been served well. In relation to production, the current IP protections, coupled with different regulatory approvals, have resulted in an oligopolistic market, dominated at present by a small number of vaccine makers, including: Pfizer/BioNTech, AstraZeneca/Oxford, Johnson \& Johnson, Moderna, Curevac, as well as Sputnik (Russia), Sinovac (China) and Covaxin (India).216 As we explore in the next sub-section, many of them have refused offers by experienced producers, such as Teva, to collaborate by assisting in manufacturing to produce more vaccines. ${ }^{217}$ It is not surprising that this small number of manufacturers with growing, but still relatively limited, voluntary licensing arrangements have struggled to meet the need to vaccinate the world against COVID-19. These monopolies appear to

211 D Crow, 'How mRNA became a vaccine game-changer' Financial Times (13 May 2021) https://www.ft.com/content/b2978026-4bc2-439c-a561-a1972eeba940

212 PhRMA, 'PhRMA Statement on the WTO TRIPS IP Waiver' (May 2021) https://www.phrma.org/PressRelease/PhRMA-Statement-on-WTO-TRIPS-Intellectual-Property-Waiver ("handing over American innovations to countries looking to undermine our leadership in biomedical discovery').

213 We acknowledge that there are different conceptions of proportionality, some of which are better suited to understanding intended and unintended, domestic and cross-national consequences of the application of the rules under the TRIPS agreement. Our argumentation is supported by constructions of proportionality that provide resources for analysing ends and means, rather than narrower constructions of 'balancing' options. To claim the TRIPS waiver is proportionate, is to claim a cumulative view of historic and ahistoric factors of both positive and negative effects to evaluate moral weight or permissibility of a chosen act. See for instance M Luteran 'The Lost Meaning of Proportionality' in Huscroft, Miller and Webber Proportionality and the Rule of Law: Rights, Justification, Reasoning (Cambridge University Press, 2014), 21-42

214 On proportionality analysis, it is worth recalling that under the European Convention on Human Rights and EU Charter of Fundamental Rights, IP rights are qualified rights, not absolute rights - see J Griffiths and L McDonagh, 'Fundamental Rights and European Intellectual Property Law - The Case of Art 17(2) of the EU Charter' in C Geiger (Ed.), Constructing European IP: Achievements and New Perspectives (Edward Elgar, 2013) 75-93.

215 On the need to conceive of the 'public' in intellectual property law's narrative as a 'global public': HY Kang, 'Patent capital in the covid-19 pandemic' Critical Legal Thinking blog (9 February 2021) https://criticallegalthinking.com/2021/02/09/patent-capital-in-the-covid-19-pandemic-critical-intellectualproperty-law/

216 There are several other vaccine candidates in various stages of trial, as shown in 'Coronavirus Vaccine Tracker' The New York Times (updated 21 May 2020) https://www.nytimes.com/interactive/2020/science/coronavirusvaccine-tracker.html

217 A Furlong, 'Big vaccine makers reject offers to help produce more jabs' Politico (14 May 2021) https://www.politico.eu/article/vaccine-producers-reject-offers-to-make-more-jabs/ 
be operating contrary to the global public interest in a pandemic, and as such, there should be incentives and mandates for new competitors to enter the market to increase production of a scarce good.

On price, as noted above, the current IP legal order upholds a system whereby LMICs, such as South Africa, Bangladesh and Uganda have reportedly been charged a higher price than HICs for vaccines. ${ }^{218}$ On pricing, Hilty et al. state: 'In the abstract, there was certainly a risk of excessive prices when the vaccines were still under development. Such risk should have been addressed by governments in the framework of the contracts subsidising research on vaccines ...'219

It is true that, despite significant public subsidies and effective de-risking of COVID19 vaccines through advance market orders, governments have not taken an ownership interest in the IP or demanded, for example, a royalty in the private profit that these subsidies yield. ${ }^{220}$ Ideally, contractual clauses in, for example, public funding agreements providing for developing underlying technologies related to COVID-19 vaccines should have been adopted, and should have built in affordability and non-exclusive use clauses for any downstream IP arising from such research and development. For future vaccines, we would strongly advocate that government investment and academic partnerships be equipped to include such clauses and to enforce them.

Nonetheless, the argument of Hilty et al. is offered on the basis of hindsight, with a lack of critical analysis of the link between IP and pricing power, and fails to offer an adequate solution for present (and future) pandemic situations. ${ }^{221}$ Inequalities of pricing and distribution are matters of grave concern that must not be minimised or explained away as if they do not relate to intellectual property law. To portray the question of vaccine affordability as a matter of private contractual choices is to selectively ignore that a patent right bestows the exclusionary right and, hence, the power of monopoly pricing on the patent holder, which affects how such contracts are negotiated asymmetrically. ${ }^{222}$ From a pragmatic and ethical perspective, our key goal at this time must be to suggest a way forward in light of the position we are now in rather than defending lex lata that has shown its fatal limitations. As access to medicines campaigners and patent scholars have pointed out in many different ways, intellectual property is the fundamental structure that underlies

\footnotetext{
${ }^{218} \mathrm{C}$ Paun and A Furlong, 'Poorer countries hit with higher price tag for Oxford/AstraZeneca vaccine' Politico (22 February 2021) https://www.politico.eu/article/astrazeneca-vaccine-cost-higher-in-poorer-countriescoronavirus/

${ }^{219}$ RM Hilty, PHD Batista, S Carls, D Kim, M Lamping and PR Slowinski, 'Covid-19 and the Role of Intellectual Property: Position Statement of the Max Planck Institute for Innovation and Competition of 7 May 2021' (7 May 2021) at https://www.ip.mpg.de/fileadmin/ipmpg/content/stellungnahmen/20210507_Position_statement Covid I P waiver.pdf

220 P Patnaik and HY Kang, 'The “Patent Bargain”, Public Good \& COVID19' Healthpolicy Watch News (26 April 2021) https:// healthpolicy-watch.news/the-patent-bargain-public-good-covid-19/

221 RM Hilty, PHD Batista, S Carls, D Kim, M Lamping and PR Slowinski, 'Covid-19 and the Role of Intellectual Property: Position Statement of the Max Planck Institute for Innovation and Competition of 7 May 2021' (7 May 2021) https://www.ip.mpg.de/fileadmin/ipmpg/content/stellungnahmen/2021 0507 Position statement Covid I P waiver.pdf

222 O Dyer, 'Covid-19: Countries are learning what others paid for vaccines' BMJ (29 Jan 2021)
} 
Thambisetty, McMahon, McDonagh, Kang, Dutfield
The TRIPS Intellectual Property

Waiver Proposal

and enables such inequities, because it gives IP holders monopoly rights to control the use of underlying technologies. 223

We cannot divorce the layering of intellectual property rights, exclusivity protections around regulatory data, and the legal construction of excessive incentives from pricing; we cannot distinguish a culture of trade secrecy from absent transparency; we cannot rely on the free market to provide equitable distribution of vaccines globally any more than we relied on the free market to fund the necessary $R \& D$ or bear the whole risk of developing such vaccines in the first place. It is vital that rather than critiquing the TRIPS waiver proposal in legal formalistic terms, we locate it (and other current proposals) within their broader social, economic and political context. We must ground such proposals in the reality that each day that we do not have global equitable access to vaccines, the health, economic and social implications of COVID-19 will worsen, and in effect, more lives will be lost. To achieve global equity in vaccine access, we must scrutinise IP law as it operates alongside other legal/regulatory protections/systems and find solutions in tandem with addressing excessive pricing, lack of transparency and inequitable distribution. Hence, it is vital in this context that we as IP scholars work together in tackling the entrenched inequalities of the global economy, which the IP system reinforces. These have been evident in TRIPS since its inception. ${ }^{224}$ Rather than narrowly confining legal interpretation to existing legal clauses in TRIPS that have proven to be woefully inadequate in times of pandemic need, we ought to use our knowledge to propose alternative approaches to the current crisis, as the existing legal status quo is contributing to disastrous moral and political consequences of vaccine injustice.

This illustrates an important point: the TRIPS waiver - indeed TRIPS itself - is not only legal, but also political. To view the waiver proposal solely in legal formalist terms is to make a categorical error. ${ }^{225}$ The history of both the TRIPS negotiations and the 2001 Doha Declaration process demonstrates how IP law cannot be separated from global political economy and broader concerns of public interest. ${ }^{226}$ The TRIPS waiver proposal carries with it a unique resonance in the political-economic sphere. The change in discourse around IP which the waiver discussions are causing has the ability to bring greater clarity to the overall political legitimacy of IP law, and potentially shift the way domestic public health concerns can be strengthened against IP monopolies, including on the issue of pricing. There are a range of ways, from encouraging greater transparency to boosting production volume, that the TRIPS waiver, and attendant discussions, could have

${ }^{223}$ KC Shadlen, Coalitions and Compliance: The Political Economy of Pharmaceutical Patents in Latin America (Oxford University Press, 2017); A McMahon, 'Biotechnology, Health and Patents as Private Governance Tools: The Good, the Bad and the Potential for Ugly?' Intellectual Property Quarterly (2020) 161.

224 S Oddi, 'TRIPS - Natural Rights and a Polite Form of Economic Imperialism' 29 Vanderbilt Journal of Transnational Law (1996) 415.

${ }^{225}$ RM Hilty, PHD Batista, S Carls, D Kim, M Lamping and PR Slowinski, 'Covid-19 and the Role of Intellectual Property: Position Statement of the Max Planck Institute for Innovation and Competition of 7 May 2021' (7 May 2021)

https://www.ip.mpg.de/fileadmin/ipmpg/content/stellungnahmen/20210507 Position statement_Covid I P waiver.pdf

226 SK Sell, Private Power, Public Law: The Globalization of Intellectual Property Rights (Cambridge University Press, 2003). 
a beneficial impact on the pricing of vaccines. In this regard, David Malpass, World Bank president, suggests the creation of a mandatory database about vaccine price and volume to help achieve price equity. 227 We support this proposal as a useful addendum to the TRIPS waiver.

\section{BUILDING PRODUCTIVE AND INNOVATIVE CAPACITY IN BOTH HICS AND LMICS: TOWARDS LONG-TERM AND SUSTAINABLE VACCINE SUPPLIES}

One of the arguments raised against the TRIPS waiver proposal is that it will not help to alleviate the current vaccine shortage because it will take a long time to build local manufacturing capacity in LMICs; and in the meantime, existing HIC/LMIC facilities may be at, or near, capacity. 228 Both of these points require unpacking. On the first - building new LMIC capacity - it is true that some new investments in LMICs' production would not have immediate impact. It could take some months before vaccine manufacture can begin at entirely new or vastly repurposed facilities. Yet, other factories can be brought up to speed much more readily. 229 For example, it is evident that in India the potential exists to scale up manufacturing capacity at several factories. ${ }^{230}$ The country has up to 21 vaccine facilities, both private- and public-sector funded, many with the existing ability to export vaccines to meet the demands of $\mathrm{UN}$ agencies.

On the notion that there is no spare HIC/LMIC production capacity, this is contested. Companies in both HICs and LMICs - Canada (Biolyse), Israel (Teva), Denmark (Bavarian Nordic) and Bangladesh (Incepta) - have offered manufacturing capacity and were rebuffed and/or were unable to obtain a licence. ${ }^{231}$ That such HIC and LMIC capacity offers have not been taken up goes against what many industry sources, and even some IP commentators, have argued in recent weeks and months - that the appropriate 'spare' facilities do not exist elsewhere, and that new capacity could not be

227 G Tett, 'How radical transparency can help vaccinate the world' Financial Times (15 May 2021). https://www.ft.com/content/c2ba2620-1785-434f-a574-7d54036f8182

${ }^{228}$ International Federation of Pharmaceutical Manufacturers and Associations, 'Towards Vaccinating the World Landscape of Current Covid-19 Supply Chain and Manufacturing Capacity, Potential Challenges, Initial Responses, and Possible "Solution Space" - A Discussion Document' (embargoed and released on 9 March 2021) https://www.ifpma.org/wp-content/uploads/2021/03/Summit Landscape Discussion Document.pdf. See also H Kuchler, 'Will a Suspension of Covid Vaccine Patents Lead to More Jabs?' Financial Times (6 May 2021) https://www.ft.com/content/b0f42409-6fdf-43eb-96c7-d166e090ab99

${ }^{229}$ For an overview of potential manufacturing sites that could be used to upscale COVID-19 vaccine production, see details provided by KEI at https://www.keionline.org/covid-19-vaccine-manufacturing-capacity

230 P Rajan and M Neelakantan, 'Scaling Up Vaccine Production' The Hindu (13 April 2021) https://www.thehindu.com/opinion/op-ed/scaling-up-vaccine-production/article34304767.ece

${ }^{231} \mathrm{~N}$ Asgari, 'Teva says vaccine makers have not taken its offer to help produce jabs' Financial Times (28 April 2021) https://www.ft.com/content/4c72242f-fb8b-4c1c-b19e-f5c199b8e3a7; A Furlong, 'US Shift of Vaccines Embarrasses Europe before India Summit' Politico (6 May 2021) https://www.politico.eu/article/coronavirusvaccine-patent-europe-united-states-joe-biden-india-summit/; J Oaten, 'Vaccine Makers Say Coronavirus Could Be Stopped around the Globe in Months Rather than Years. Here's How' ABC News (19 March 2021) https://www.abc.net.au/news/2021-03-20/how-we-end-the-covid-pandemic-around-the-world-inmonths $/ 13260178$ 
Thambisetty, McMahon, McDonagh, Kang, Dutfield
The TRIPS Intellectual Property

Waiver Proposal

built for years. ${ }^{232}$ Despite the fact that the pandemic is not going to be over anytime soon - and that for it to be brought to an end global equitable vaccine access is vital - time is being lost by not accepting such voluntary offers and maximising co-operation for COVID-19 vaccine production globally.

It has also been claimed that it is risky for vaccines to be produced in countries where intellectual property rights are 'weak' on the basis that the resulting vaccines may not be genuine or safe. ${ }^{233}$ Such claims appear to attempt to equate intellectual property rights with product quality. However, an IP right is not related to the quality of the underlying technology or product - these are entirely separate issues.234 Moreover, decades of examples prove otherwise in the vaccine context. ${ }^{235}$ For instance, Tamiflu was produced safely and successfully in a short space of time in India in 2005 despite claims that it involved such a complex process that could not be easily replicated. ${ }^{236}$ Similarly, Indian company Shanta Biotechnics produced a reliable and safe recombinant hepatitis B vaccine in 2009.237 Last year, Hetero and CIPLA produced Remdesivir in India after similar claims about safety fears and lack of biologics manufacturing competences were made. ${ }^{238}$ Assertions that it would take 'four years' to build reliable pharmaceutical capacity in a country like Bangladesh are, quite simply, inaccurate (see the example of Incepta above). ${ }^{239}$ In fact, a study involving vaccine makers and their supply to Gavi, a private-public vaccine alliance, found that transnational IP rights impede new manufacturers from entering and competing in the market rather than such manufacturers being held back by an inherent lack of manufacturing and technological capability. ${ }^{240}$

There has been a related claim that the global shortage of raw materials worldwide is more to blame than intellectual property rights for the current lack of COVID-19 vaccine

232 H Kuchler, 'Will a Suspension of Covid Vaccine Patents Lead to More Jabs?' Financial Times (6 May 2021) https://www.ft.com/content/b0f42409-6fdf-43eb-96c7-d166e090ab99

233 S Gottlieb, 'Covid Lessons from Bush's Effort Against AIDS' Wall Street Journal (28 March 2021).

234 M Llewelyn, 'Schrodinger's Cat: An Observation on Modern Patent Law' in P Drahos (Ed.), Death of Patents (Lawtext Publishing, 2005).

235 There are several key examples in Brazil, China and India as outlined in RG Douglas and VB Samant, 'The

Vaccine Industry' 41 Plotkin's Vaccines (2018) - doi:10.1016/B978-0-323-35761-6.00004-3.

$236 \mathrm{~T}$ Amin, 'The Folly of Hoarding Knowledge in the COVID-19 Age: Let Vaccine Producers in Poor Countries Help End the Pandemic' Foreign Affairs (29 Jan 2021) https://www.foreignaffairs.com/articles/world/2021-0129/folly-hoarding-knowledge-covid-19-age

${ }^{237} \mathrm{~J}$ Chakma, H Masum, K Perampaladas, J Heys and PA Singer, 'Indian vaccine innovation: the case of Shantha Biotechnics' Globalization and Health 7 (2011) https://www.ncbi.nlm.nih.gov/pmc/articles/PMC3110116/

238 'Remdesivir: Five Indian and Pakistani firms to make drug to "fight coronavirus" BBC (14 May 2020) https://www.bbc.co.uk/news/world-asia-india-52659052; 'How secret deals could keep a COVID-19 drug out of reach for millions' Los Angeles Times (1 July 2020) https://www.latimes.com/worldnation/story/2020-07-01/gilead-patent-limits-access-to-covid-19-drug-remdesivir

${ }^{239}$ See comment of Professor Sir Robin Jacob in H Kuchler, 'Will a suspension of Covid vaccine patents lead to more jabs?' Financial Times (6 May 2021) https://www.ft.com/content/b0f42409-6fdf-43eb-96c7-d166e090ab99. Contrast this with the offer of Bangladeshi company Incepta, as noted in 'Countries Call on Drug Companies to Share Vaccine Know-how' The Independent (1 March 2021) https://www.independent.co.uk/news/countries-callon-drug-companies-to-share-vaccine-knowhow-european-union-who-countries-vaccine-bangladeshb1809054.html

${ }^{240}$ S Chandrasekharan, T Amin, J Kim, E Furrer, A-C Matterson, N Schwalbe and A Nguyen, 'Intellectual property rights and challenges for development of affordable human papillomavirus, rotavirus and pneumococcal vaccines: Patent landscaping and perspectives of developing country vaccine manufacturers' 33 Vaccine (2015) 6366. 
supply. ${ }^{241}$ On this, a recent open letter by Pfizer CEO Albert Bourla, published in part as a response to the US announcement of support for a TRIPS wavier proposal, is relevant. In this letter Bourla makes clear that the problem of vaccine supply is not one of building capacity and converting facilities (notably, mRNA vaccine capacity was built in a matter of months in 2020). Instead, he argues that shortages of raw material and supply chain components are the real problems. ${ }^{242}$ Bourla's point thereby disproves the claim, discussed above, that it would take years to build up vaccine production capacity. Yet, in focusing on materials and components, Bourla fails to acknowledge that material and component shortages are not unrelated to bottlenecks created by an oligopolistic market, featuring too little standardisation, and amid an existing patent thicket. Vaccine technology components range from the mundane to the sophisticated, and there are many different trajectories of IP that may be implicated, including in the logistics of distribution. ${ }^{243}$ For example, plastic, single-use bioreactor bags have been scarce due to the global dependency on a few suppliers for these materials; crucially, there are currently 2800 patents that cover them, making entering the market as a new supplier onerous. ${ }^{244}$ The TRIPS waiver, proposed by India and South Africa in October 2020, and revised in May 2021, ${ }^{245}$ would apply not just to vaccine end products but also, potentially, to mechanical equipment and components; moreover, international negotiations over the waiver could be the springboard for coordinating the global supply of ingredients efficiently. ${ }^{246}$

In fact, Article 66.2 of TRIPS obliges governments in developed countries to provide incentives to 'enterprises and institutions' to enable technology transfer and a 'sound and viable technological base'. The reluctance to share not just in the end products (including drugs or vaccines) but the underlying technology transfer has been a consistent failure of the TRIPS settlement and has arguably prolonged the capacity of a small number of large companies to manipulate artificial scarcity globally. ${ }^{247}$

It is true, and we readily acknowledge, that the manufacturing processes for the COVID-19 vaccines can be complex and varied depending on the type of vaccine involved; delays in the supply of materials can also create bottlenecks; and successful

241 A Bourla, 'Today I Sent this Letter to Have a Candid Conversation with our Colleagues about the Drivers of COVID-19 Access and Availability' Open Letter published on LinkedIn on 7 May 2021

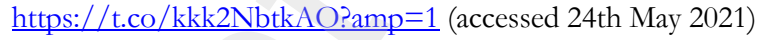

242 A Bourla, 'Today I Sent this Letter to Have a Candid Conversation with our Colleagues about the Drivers of COVID-19 Access and Availability' Open Letter published on LinkedIn on 7 May 2021 https://t.co/kkk2NbtkAO?amp=1 (accessed 24th May 2021)

${ }^{243}$ M Stoller and D Barclay, 'Why are there Shortages of Plastic Bags needed for Vaccine Production? Monopolies and Patents' Substack (11 May 2021) https://mattstoller.substack.com/p/why-are-there-shortages-of-plastic

${ }^{244} \mathrm{M}$ Stoller and D Barclay, 'Why are there Shortages of Plastic Bags needed for Vaccine Production? Monopolies and Patents' Substack (11 May 2021) https://mattstoller.substack.com/p/why-are-there-shortages-of-plastic

245 See revised TRIPS waiver text of 21 May 2021 at https://www.keionline.org/wpcontent/uploads/W669Rev1.pdf

${ }^{246}$ D Sengupta, 'Pat(i)ent rights: Will waiver of IP rights on Covid Vaccines, Drugs Help Developing Nations like India?' Economic Times (11 May 2021) https://economictimes.indiatimes.com/news/morning-briefpodcast/morning-brief-patient-rights-will-waiver-of-ip-rights-on-covid-vaccines-drugs-help-developingnations-likeindia/podcast/82539966.cms?utm source $\% 3$ Dwhatsapp web $\% 26$ utm medium $\% 3$ Dsocial $\% 26$ utm campaign $\% 3$ Dsocialsharebuttons

247 S Oddi ‘TRIPS - Natural Rights and a Polite Form of Economic Imperialism’ 29 Vanderbilt Journal of Transnational Law (1996) 415. 
Thambisetty, McMahon, McDonagh, Kang, Dutfield
The TRIPS Intellectual Property

Waiver Proposal

production requires tacit know-how. The recent wasteful production at a US factory manufacturing the Johnson \& Johnson vaccine demonstrates the reality of these challenges. ${ }^{248}$ These are all the more reasons to enhance global collaboration on vaccine manufacture for COVID-19 and to establish more production sites around the world so that sudden shortfalls in one can be made up for in others. Merely repeating claims that LMICs do not have the suitable productive facilities masks the root problem: not enough productive capacity has been built or is being built right now. Despite the pandemic, vaccine makers and pharmaceutical companies who hold relevant rights over COVID-19 vaccines have not participated in any voluntary calls to pool patents and know-how even though a proposed facility to do so, C-TAP, has existed for a year. In the absence of such industry co-operation, mandatory solutions are needed. The TRIPS waiver offers an opportunity to change this.

Pandemic management and preparedness from here on entails improving urgently the capacity of LMICs to produce the knowledge and inventions they need. It is morally problematic to invoke manufacturing capacity limitations in LMICs in order to defend a status quo that has served the global public very poorly in the COVID-19 pandemic. Not only does such a broad-brush generalisation of countries outside Europe or North America as merely 'developing' underplay excellent existing facilities in Brazil, China and India, for example, but it also fails to envisage a better and more equitable patent system, and a more effective future pandemic response than we have witnessed thus far with COVID-19.249 Even if some countries do not currently have the requisite technology for vaccine production, it is in everyone's interest that capacity be built up and technology transferred as soon as possible to enable current and future production of vaccines or drugs to be ramped up globally. ${ }^{250}$ If not now, in the face of a pandemic, then when?251

\section{CONCLUSION}

More than one year since the start of the COVID-19 pandemic, the rising death toll and emergence of variants of concern across the world have already laid bare the dire consequences of insufficient vaccine production and inequitable distribution between the

\footnotetext{
248 T Dai, 'Why Johnson and Johnson throwing out 15 million covid-19 vaccine doses shouldn't scare you' The Conversation (1 April 2021) https://theconversation.com/why-johnson-and-johnson-throwing-out-15-millioncovid-19-vaccine-doses-shouldnt-scare-you-158300

${ }^{249}$ S Parthasarathy, Patent Politics: Life Forms, Markets and the Public Interest in the United States and Europe (Chicago University Press, 2017) at 16-17, 113 and 196. See also P Krishtel, 'The Path To Racial Justice runs through this Agency' The New York Times (9 Feb 2021) https://www.nytimes.com/2021/02/09/opinion/biden-patentoffice.html

${ }^{250}$ In this context, our intention is not that there would be a scale up in all LMICs immediately for COVID-19; but rather we mean that where feasible and practical, we support the spreading of manufacturing for vaccines more equally and equitably across HICs and LMICs. See A Irwin, 'How Covid Spurred Africa to plot a Vaccines Revolution' Nature (21 April 2021) https://www.nature.com/articles/d41586-021-01048-1

${ }^{251} \mathrm{~T}$ Amin, 'The Folly of Hoarding Knowledge in the COVID-19 Age: Let Vaccine Producers in Poor Countries Help End the Pandemic' Foreign Affairs (29 Jan 2021) https://www.foreignaffairs.com/articles/world/2021-0129/folly-hoarding-knowledge-covid-19-age
} 
HICs and the LMICs. ${ }^{252}$ An immediate and globally co-ordinated multi-pronged approach to increase vaccine production and distribution capacity is urgently needed. In the absence of the required voluntary pharmaceutical co-operation needed to vastly increase global supplies to meet current demands, the TRIPS waiver proposal represents an important step and can operate as a legal and political lever to balance industry's interests against those of the global public with the goal being to bring the pandemic to an end as soon as possible (and prepare for future ones).

Although we realise that it will not, by itself, solve intractable issues caused by technical and material shortages, the TRIPS waiver is necessary in order to clear the way from IP legal constraints for companies and research institutions to develop and produce vaccines and other health technologies in the fight against COVID-19 without fear of litigation. In terms of the law, the next step is to negotiate the text-based agreement at the WTO. This may not go as planned. The text may end up unworkable in practice, as happened with the Doha Declaration in 2001 and the resulting TRIPS Amendment. ${ }^{253}$ The recent refusal of the G20 to commit to negotiation of a text may not bode well. ${ }^{254}$ Nonetheless, we urge all WTO members to confront the seriousness of the COVID-19 emergency and achieve a workable text that genuinely 'clears the way' for radical upscaling of production of such vaccines and other health technologies globally, and that enables vaccine equity for (and production of doses in) LMICs.

Beyond a legal text, the TRIPS waiver has become a masthead signalling a lot of different kinds of political-economic actions that now need to flow. We need a multipronged approach: addressing the over-ordering of doses and hoarding in HICs; coordinating supply chains to increase production globally; investing in C-TAP and WHO's mRNA technology transfer hub; encouraging companies, even paying them if necessary, to enter into voluntary transfers; streamlining regulatory approval processes and sharing exclusive data from regulatory dossiers. All of this now needs to happen simultaneously. Resolving the global vaccine production and supply problem is a matter of extreme urgency. It is a tremendous challenge, but it is not insurmountable.

While there are many advantages to achieving greater legal clarity on intellectual property rights and enabling the facilitation of technology transfer that may emerge in the wake of a TRIPS waiver, what is just as significant is that the waiver has provoked a global discussion about IP incentive systems and their limits, especially regarding - but not limited to - vaccines. It has shifted the terms of debate in that it places the onus on the pharmaceutical industry to offer greater transparency about production and pricing. ${ }^{255}$ The

252 P. Beaumont, 'Why India's worsening Covid crisis is a dire problem for the world' The Guardian (25 April 2021) https://www.theguardian.com/world/2021/apr/25/the-world-must-act-indias-covid-crisis-is-a-dire-problemfor-us-all

253 G Dutfield, 'Delivering Drugs to the Poor: Will the TRIPS Amendment Help?' 34 American Journal of Law and Medicine (2008) 107.

254 S Usdin, 'Shunning Biden's IP waiver, G20 supports voluntary licensing of COVID-19 vaccines' Biocentury (21 May 2021) https://www.biocentury.com/article/636569/shunning-biden-s-ip-waiver-g20-supports-voluntarylicensing-of-covid-19-vaccines

255 See the point made by Daniel Gervais that the waiver 'conversation' is helping to create more transparency about pharma manufacturing capacity in the context of COVID-19 vaccines in D Gervais, 'The TRIPS Waiver Debate: Why, and where to from here?' IPKat (20 May 2021) https://ipkitten.blogspot.com/2021/05/guest-post-tripswaiver-debate-why-and.html; See also discussion of the 'open' technology-sharing model of Oxford/AZ, 
Thambisetty, McMahon, McDonagh, Kang, Dutfield
The TRIPS Intellectual Property

Waiver Proposal

waiver debate may also lead to improved transparency about crucial raw material and supply chain issues. It has redrawn the fault lines around global IP, drawing support from unexpected quarters - including from Nobel Prize-winning economists Paul Krugman and Joseph Stiglitz, ${ }^{256}$ Pope Francis, ${ }^{257}$ and the President of the United States. ${ }^{258}$ Beyond the time that it will take to negotiate the proposed TRIPS waiver, we urge that this positive momentum towards change in the political-economic structure around TRIPS must not be allowed to dissipate. The TRIPS waiver debate ought to trigger systematic change in our vaccine and health technology landscape. The broken TRIPS promise of technology transfer from HICs to LMICs must now be fulfilled.

Beyond all this, the intense participation by civil society, notable figures and political leaders of all hues and nationalities has brought many issues into the public eye concerning how IP rights are granted, used and sometimes abused. Robust academic critiques of domestic IP regimes in wealthy countries abound, with an eye for the needs of the global public good - these are now getting an airing with those who understand that governance, capitalism and market dysfunctions cannot be separated from intellectual property law. This is not the time to insist on a narrow legal formalism, ${ }^{259}$ but to interpret and understand intellectual property law in its original broader public purpose. ${ }^{260}$ Patents are not ends in themselves; they are a means to an end: a public good. In the midst of a pandemic, if that good can be better served globally by waiving patents and other IP rights, we as a global community of IP scholars are compelled to support this. No one is safe until everyone is safe. Unlike human life, IP rights are not inviolable. ${ }^{261}$

compared positively with the Pfizer/BioNTech model (though as we note above, even the Oxford/AZ model has significant drawbacks) in L Richardson, 'Time for other vaccine makers to follow Oxford/AstraZeneca's lead' Financial Times (18 May 2021) https://www.ft.com/content/65856fab-e394-4407-adf9-63edd8acdad3; See also H Summers, 'Britain in talks to waive Covid vaccine patents to improve global access to jabs' The Guardian (21 May 2021) https://www.theguardian.com/global-development/2021/may/20/britain-in-talks-to-waivecovid-vaccine-patents-to-improve-global-access-to-jabs

256 'Ex-leaders, Nobel Winners Urge US to Back Covid Vaccine Waiver' Reuters (14 April 2021) https://www.reuters.com/world/us/ex-leaders-nobel-winners-urge-us-back-covid-vaccine-waiver-2021-04-14/

257 R McKie, 'Pope adds voice to call for pharma giants to waive vaccine patents' The Guardian (9 May 2021) https://www.theguardian.com/world/2021/may/09/pope-adds-voice-to-call-for-pharma-giants-to-waivevaccine-patents

258 A Heidt, 'Biden Administration Backs Vaccine Intellectual Property Waiver' The Scientist (10 May 2021) https://www.the-scientist.com/news-opinion/biden-administration-backs-vaccine-intellectual-property-waiver68751

${ }^{259}$ RM Hilty, PHD Batista, S Carls, D Kim, M Lamping and PR Slowinski, 'Covid-19 and the Role of Intellectual Property: Position Statement of the Max Planck Institute for Innovation and Competition of 7 May 2021' (7 May 2021)

https://www.ip.mpg.de/fileadmin/ipmpg/content/stellungnahmen/2021 0507 Position statement_Covid_I $\underline{P}$ waiver.pdf

260 P Erfani, LO Gostin and V Kerry, 'Beyond a symbolic gesture: What's needed to turn the IP waiver into Covid19 vaccines' Stat News (19 May 2021) https://www.statnews.com/2021/05/19/beyond-a-symbolic-gesturewhats-needed-to-turn-the-ip-waiver-into-covid-19-vaccines/

${ }^{261}$ D Scally, 'Curevac investor sees bright future for German vaccine maker' The Irish Times (20 May 2021) https://www.irishtimes.com/business/health-pharma/curevac-investor-sees-bright-future-for-german-vaccinemaker-1.4568758 


\section{Declaration of Interests:}

Dutfield, Kang, McDonagh and Thambisetty confirm that there are no known conflicts of interest associated with this paper. Aisling McMahon is a member of Access to Medicines Ireland (AMI), a voluntary membership group of Comhlámh. The views expressed here are the authors' own and are not representative of AMI.

\section{Declaration of Current Funding:}

Graham Dutfield is not in receipt of any research funding.

Hyo Yoon Kang receives funding from the European Research Council project 'Patents as Scientific Information'. This publication is not connected to the project.

Aisling McMahon currently holds funding from the Irish Research Council (New Foundations Scheme) (2021), Maynooth University MUSSI Institute (2021), and Enterprise Ireland (H2020 Preparation scheme) (2021). This publication is not connected with these projects.

Luke McDonagh receives funding from the European Union Horizon2020 'INBOTS' project (2018-21) and has performed paid consultancy during this academic year (202021) for the Innovators Network Foundation for research on standard-essential patents and information technology. This publication is not connected to either of these projects.

Siva Thambisetty holds an LSE Knowledge Exchange and Impact grant. This publication is not linked to that project. 